INRA Prod. Anim., 2010, 23 (1), 23-42

\title{
Epigénétique et construction du phénotype, un enjeu pour les productions animales?
}

H. JAMMES, J.-P. RENARD

INRA, UMR1198 Biologie du Développement et Reproduction, F-78352 Jouy-en-Josas, France ENVA, Biologie du Développement et Reproduction, F-94704 Maisons-Alfort, France

Courriel : helene.jammes@jouy.inra.fr

L'épigénétique s'intéresse aux interactions entre le génome et son environnement. Tirant bénéfice des technologies d'analyses moléculaires à haut débit, la recherche en épigénétique met en évidence l'importance du pouvoir de régulation adaptative des génomes et génère un flot de données moléculaires qui pourraient devenir de nouvelles covariables en sélection animale.

L'épigénétique s'intéresse aux mécanismes moléculaires et cellulaires qui contribuent au phénotype sans modification du génotype. Ce champ disciplinaire de la biologie concerne l'aptitude qu'ont les organismes vivants à modifier l'activité de leurs gènes en réaction à des changements de leur environnement. De nombreux mécanismes régulent l'activité des gènes. Mais pour être considérés comme des mécanismes épigénétiques ils doivent être transmis de cellules en cellules à travers les mitoses de façon à pouvoir affecter un caractère phénotypique à partir d'un tissu, d'un organe ou de l'organisme entier. Des modifications épigénétiques peuvent aussi être transmises au cours de la méiose poussant alors à revisiter certains paradigmes de la transmission des caractères, notamment des caractères complexes auxquels s'intéresse l'élevage. La place de l'épigénétique dans les processus évolutifs fait l'objet de nombreux débats, mais cet aspect fondamental de l'évolution naturelle des espèces en relation avec leur environnement n'est pas directement abordé ici. Notre objectif est de montrer en quoi l'épigénétique pourrait être considérée comme une nouvelle composante de la sélection animale et devenir un enjeu pour la valorisation des espèces d'élevage.

\section{1 / Qu'est-ce que l'épigéné- tique ?}

L'épigénétique étudie la dynamique de l'organisation de la chromatine (assemblage de protéines qui entourent la molécule d'ADN) et lui confèrent une organisation tridimensionnelle au sein du noyau des cellules. Elle décrypte le rôle des modifications des composants de l'ADN (comme par exemple la méthylation des cytosines), celui des assemblages de protéines, les histones (autour desquelles s'enroulent l'ADN) et des ARN non-codants dans l'héritabilité de la lecture de l'information génétique. Contrairement aux mutations, ces modifications n'affectent pas les séquences nucléotidiques de l'ADN, mais seulement le niveau d'expression des gènes.

Historiquement, le terme «épigénétique», issu de la contraction des mots «épigénèse» et «génétique», a été utilisé en première intention en 1942 par Conrad Waddington (cf. Slack 2002), qui propose alors l'idée selon laquelle «le développement et l'évolution peuvent être considérés comme une succession d'états relativement stables séparés par des périodes d'instabilité et de changements» et définit «l'épigénétique comme la branche de la biologie qui étudie les interactions causales entre les gènes et leurs produits, responsables de l'existence du phénotype». Le phénotype d'un organisme vivant est la résultante de l'activité de son génome et de l'action de l'environnement (du milieu) dans la régulation de ces activités. A partir des années 70, le terme d'épigénétique a été utilisé pour décrire les mécanismes moléculaires associés à des modifications de l'activité des gènes, héritables à travers la mitose voire la méiose et sans changement de la séquence des nucléotides (Goldberg et al 2007). Comme nous le verrons plus loin, une des caractéristiques essentielle de l'épigénétique est la dualité entre stabilité et réversibilité.

Les cellules peuvent contrôler très finement leur milieu intérieur (homéostasie) en utilisant directement et de façon séquentielle les métabolites de leur environnement. La modélisation des mécanismes à partir du concept de l'opéron lactose proposé il y a 50 ans par Jacob et Monod (1961) montre que les cellules peuvent s'adapter à de nombreuses variations métaboliques de leur environnement et évoluer entre des états multistables mettant en jeu une régulation transcriptionnelle transitoire sans changement de la chromatine (Santillan et Mackey 2008). Toute régulation génique n'est donc pas épigénétique. Mais quand de très nombreux gènes doivent être régulés simultanément, dans plusieurs tissus et dans le temps, alors les mécanismes épigénétiques deviennent indispensables. C'est notamment le cas au cours du développement embryonnaire et fotal quand s'établissent les patrons d'expression génique qui président à la morphogenèse. Les modifications de l'environnement métabolique, hormonal et physique de l'organisme en croissance se traduisent par des changements de forme, d'état, de mouvement ou de taux d'activité de ses tissus et organes (West-Eberhard 2005). L'organisme s'adapte à ces modifications, mais il lui faut dans le même temps assurer la réalisation du patron morphogénétique de son développement, patron strictement défini à partir des profils d'expression génique initiés après la fécondation de l'œuf (le «programme» 
génétique). Le maintien d'une cohérence dans le fonctionnement de nombreux réseaux géniques implique à la fois rigueur et souplesse, c'est-à-dire robustesse dans la dynamique de l'activité des réseaux géniques (Kitano 2004) et flexibilité dans la transcription des gènes (Ueda et al 2004). Les remaniements de la chromatine participent de ces propriétés.

Ce qui nous intéresse ici n'est pas tant le programme génétique de développement dont les défauts de réalisation peuvent compromettre le développement lui-même ou être sources d'anomalies morphologiques ou physiologiques invalidantes, que la flexibilité des réponses des réseaux de gènes à leur environnement et les modifications épigénétiques qui leurs sont associées. Plus précisément, la question est de savoir dans quelle mesure des modifications épigénétiques impliquées dans la régulation de certains gènes ou circuits géniques en réponse aux modulations ou changements de l'environnement sont réversibles conférant une certaine flexibilité adaptative à l'organisme, ou non réversibles, affectant alors plus durablement le phénotype et posant la question de l'héritabilité des caractères, c'est-à-dire la possibilité de transmission sur le long terme aux générations suivantes.

Dans ce contexte, et même si les fondements moléculaires des différentes formes de cette «plasticité fonctionnelle» du vivant restent encore peu compris (Morange 2009), l'étude des marques épigénétiques apposées de manière séquentielle sur le génome, c'est-à-dire l'épigénome, devrait permettre de pouvoir distinguer la part des variations géniques (variabilité alléliques) de celles dues à l'environnement (variabilité épigénétique) dans la réalisation du phénotype.

\section{2 / Les marques épigéné- tiques}

Par définition, les marques épigénétiques sont à la fois héritables à travers la mitose et la méiose sans modification de la séquence nucléotidique de l'ADN et réversibles. Ces processus moléculaires confèrent à la chromatine des structures particulières allant de l'hétérochromatine à l'euchromatine, dictant ou participant ainsi au silence transcriptionnel de la région ou a contrario à sa lecture.

\section{1 / La méthylation de l'ADN}

La méthylation de l'ADN est une des modifications épigénétiques la mieux

Figure 1. En présence de DNA méthyltransférase, la réaction covalente consiste en une substitution d'un des $H$ liés au carbone 5' de la désoxycytidine par un groupe CH3 lui-même fourni par la S-Adenosyl-L Méthionine (SAM), donneur universel de groupe méthyl. SAM a été découvert en 1953 par le biochimiste italien Giulio Cantoni. SAM est synthétisé à partir de la méthionine et de l'ATP en présence de méthionine adénosyl transférase.

\section{Deoxycytidine}

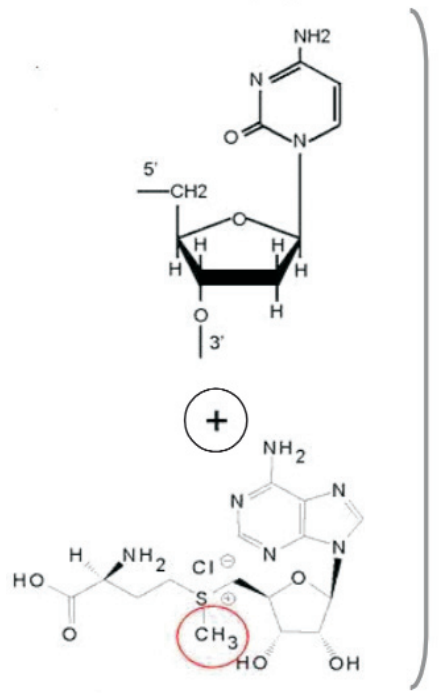

\section{S-adénosyl-L-méthionine} (SAM)
5 Méthyl-cytidine

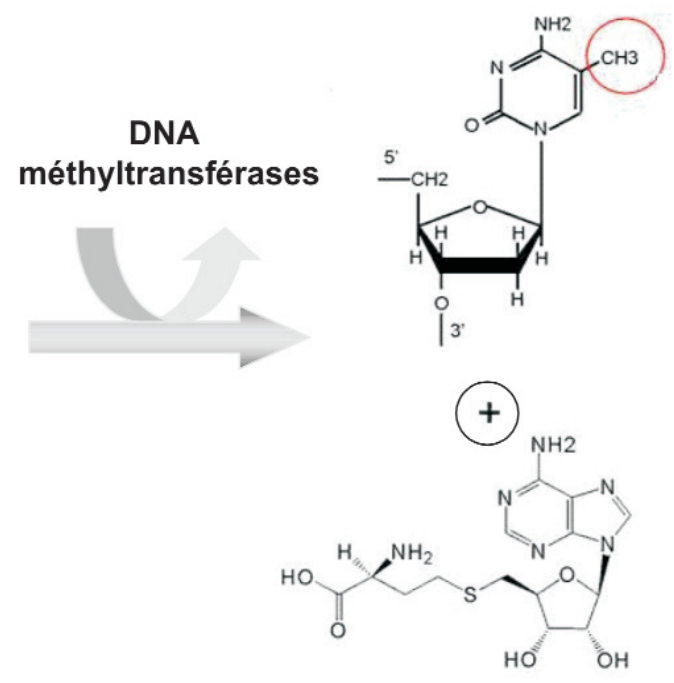

S-adénosyl-homocystéine (SAH) caractérisée participant à la «mémoire cellulaire» (Holliday et Pugh 1975, Riggs 1975, Suzuki et Bird 2008).

La méthylation touche les résidus cytosine de l'ADN et en affecte 3 à $8 \%$ chez les mammifères et jusqu'à $50 \%$ chez les plantes. Cependant, aucune méthylation de l'ADN génomique n'est détectée chez Saccharomyces cerevisiae et Caenorhabditis elegans, du fait de l'absence de gène codant pour une DNA méthyltransferase (enzyme responsable de la méthylation de l'ADN ; figure 1, tableau 1).

Chez les plantes supérieures, la méthylation des cytosines dépend de trois types de DNA méthyltransférases (Gehring et al 2007) ; chacune d'elles reconnaît un motif particulier, et participe, soit au maintien de la méthylation à la suite de la réplication de l'ADN, soit à la méthylation de novo. Les récentes analyses de la répartition des sites de méthylation révèlent que ces modifications covalentes touchent plus particulièrement les séquences répétées de l'ADN, abondantes notamment dans les régions centromériques et péricentromériques, transcriptionnellement inactives (hétérochromatine) et aussi dans les transposons. Une autre particularité du monde végétal est une forte prévalence de la méthylation des séquences en 3 ' transcrites des gènes (plus de $33 \%$ des gènes chez Arabidopsis thaliana), alors que la méthylation des séquences 5' UTR est très minoritaire. Cette méthylation intragénique («gene-body methylation») peut varier entre différents écotypes $d$ 'A. thaliana (Suzuki et Bird 2008) et à la fois rester particulièrement stable au cours de l'évolution. La méthylation de l'ADN constituerait ainsi une réponse adaptative de la plante à son environnement avec la possibilité de changements à la fois rapides et stables.

Chez l'animal, la méthylation touche les sites formés par les résidus cytosines et guanine de l'ADN (site palindromique minimal $\mathrm{CG}$ ) mais elle dépend de plusieurs DNA méthyltransférases (DMNT) ; celles-ci permettent l'apposition des marques de méthylation (rôle des DMNT de novo) ou leur maintien au cours des divisions des cellules (rôle des DNMT de maintien ; Chen et Li 2004, Schaefer et al 2007). La distribution des sites de méthylation sur l'ensemble du génome a surtout été étudiée chez l'Homme (Robertson 2005, Eckhardt et al 2006, Weber et Schülberge 2007). Les sites CG, notés $\mathrm{CpG}$, apparaissent répartis de manière homogène sur le génome et sont généralement méthylés. En revanche, les «ilots $\mathrm{CpG}$ », séquences d'ADN de l'ordre de $500 \mathrm{bp}$ riches en GC $(>60 \%)$ associées aux régions promotrices de plus de la moitié des gènes, présentent un degré de méthylation variable; ils sont considérés comme correspondants aux «gene-body methylation» des plantes. 
Tableau 1. Les DNA méthyltransférases et leur fonction, des plantes aux mammifères (Chen et Li 2004, Gehring et al 2007, Schaefer et al 2007, Suzuki et Bird 2008).

\begin{tabular}{|c|c|c|c|c|c|c|}
\hline & Espèces & Gène & Isoformes & Expression & $\begin{array}{c}\text { Activité } \\
\text { méthyltransférase }\end{array}$ & Phénotype des mutants \\
\hline \multirow[t]{2}{*}{$\begin{array}{l}\text { Classe } \\
\text { DNMT1 }\end{array}$} & Mammifères & Dnmt1 & $\begin{array}{l}\text { Dnmt1 } \\
\text { Dnmt1s } \\
\text { Dnmt1o } \\
\text { Dnmt1p }\end{array}$ & $\begin{array}{l}\text { Ubiquitaire } \\
\text { Ubiquitaire } \\
\text { Ovocyte } \\
\text { et embryon } \\
\text { préimplantatoire } \\
\text { Spermatocystes }\end{array}$ & $\begin{array}{l}\text { Activité de maintien } \\
\text { Base moléculaire } \\
\text { de l'héritabilité } \\
\text { Pas d'activité }\end{array}$ & $\begin{array}{l}\text { Déméthylation globale } \\
\text { Léthalité embryonnaire à } 9,5 \mathrm{jpc} \\
\text { Expression anormale des } \\
\text { gènes soumis à l'empreinte }\end{array}$ \\
\hline & Arabidopsis & MET1 & MET1 & Ubiquitaire & $\begin{array}{l}\text { Activité de maintien } \\
\text { (Sur les séquences } \mathrm{CpG} \text { ) }\end{array}$ & $\begin{array}{l}\text { Perte globale de la méthylation ; } \\
\text { Activation des transposons, } \\
\text { Expression anormale des gènes } \\
\text { Floraison tardive }\end{array}$ \\
\hline $\begin{array}{l}\text { Classe } \\
\text { DNMT2 }\end{array}$ & Mammifères & Dnmt2 & Dnmt2 & Ubiquitaire & $\begin{array}{l}\text { Activité limitée } \\
\text { Pourrait avoir un rôle dans } \\
\text { la méthylation des ARN }\end{array}$ & Pas de phénotype particulier \\
\hline $\begin{array}{l}\text { Classe } \\
\text { DNMT3 }\end{array}$ & Arabidopsis & $\begin{array}{l}\text { DRM1 } \\
\text { DRM2 }\end{array}$ & $\begin{array}{l}\text { Dnmt3a } \\
\text { Dnmt3b } \\
\text { Dnmt3L }\end{array}$ & $\begin{array}{l}\text { Ubiquitaire } \\
\text { Ubiquitaire } \\
\text { Cellules } \\
\text { germinales }\end{array}$ & $\begin{array}{l}\text { Activité de novo } \\
\text { Activité de novo } \\
\text { Pas d'activité } \\
\text { Régulateur de l'activité de } \\
\text { DNMT3a et de DNMT3b } \\
\text { Activité de novo (CpG, CpNpG, } \\
\text { CpNN) }\end{array}$ & $\begin{array}{l}\text { Léthalité postnatale (4 semaines); } \\
\text { Stérilité chez les mâles } \\
\text { Défaut de méthylation des gènes } \\
\text { soumis à l'empreinte } \\
\text { Léthalité embryonnaire à } 14,5 \mathrm{jpc} \text {; } \\
\text { Défauts de tube neural ; } \\
\text { Déméthylation des séquences satellites } \\
\text { Défauts de l'empreinte dans la lignée } \\
\text { germinale femelle } \\
\text { Stérilité chez les mâles } \\
\text { Défaut dans l'initiation de la méthylation } \\
\text { de novo ; Perte de la méthylation } \\
\text { Assymétrique }\end{array}$ \\
\hline
\end{tabular}

$\mathrm{Au}$ cours du développement, la méthylation des séquences $\mathrm{CpG}$ est clairement associée au silence transcriptionnel des gènes. Ce processus est impliqué dans l'inactivation d'un des deux chromosomes X chez la femelle, mais aussi dans l'expression mono-allèlique des gènes soumis à l'empreinte parentale ; il est associé aux gènes ayant un rôle central au cours du développement précoce tels que les gènes homéobox (HOX) et paired box (PAX) ou encore aux décisions de lignage cellulaire. La méthylation de l'ADN est principalement tissu-spécifique et les régions susceptibles de méthylation sont généralement conservées à travers de nombreuses espèces. On parle fréquemment de T-DMR pour «Tissue Differentially Methylated Regions» soulignant l'importance de l'identité épigénétique des cellules constituant un tissu (Song et al 2009). Il n'y a donc pas, chez un individu, un état épigénétique donné mais plusieurs épigénomes, correspondant à chaque organe et tissu de l'organisme. Mais c'est bien à partir de la mesure d'organes et de tissus contribuant au phénotype que sont sélectionnés les caractères d'élevage. Si l'on se place dans la perspective d'intégrer l'épigénétique comme paramètre de sélection, il serait pertinent d'associer, par exemple, toute analyse de la qualité de la viande à une analyse de l'épigénome du muscle prélevé.

\section{2 / Les modifications post- transcriptonnelles des histones}

Le nucléosome est l'unité fonctionnelle de la chromatine, autour de laquelle s'enroulent approximativement deux tours de la double hélice d'ADN (soit environ 147 paires de bases). Le nucléosome est en fait constitué d'un octamère de quatre histones différentes (H2A, $\mathrm{H} 2 \mathrm{~B}, \mathrm{H} 3$ et H4 ; Luger et Richmond
1998). Une abondante littérature démontre que ces histones sont les cibles de nombreuses modifications covalentes post-traductionnelles, incluant la méthylation des lysines et arginines, l'acétylation des lysines, la phosphorylation des sérines et thréonines, l'ubiquitylation et la sumoylation des lysines, l'ADP-polyribosylation de l'acide glutamique, la sésamination des arginines et l'isomérisation des prolines (Kouzarides 2007).

Les modifications les mieux caractérisées sont l'acétylation/déacétylation et la méthylation des histones. L'acétylation (ajout d'un groupement acétyl) s'effectue sur certains résidus lysine précis par des enzymes nommées Histones Acétyl Transférases (HAT). Elle est souvent associée à l'état «d'euchromatine» : en modifiant la charge d'attraction entre protéine et ADN et en relâchant la structure de la chromatine 
(décondensation) l'acétylation favorise la transcription. Cette marque est facilement réversible grâce à l'action des Histones Désacétylases (HDAC).

Le rôle répressif ou activateur de la méthylation des histones sur l'expression génique dépend du résidu touché et du niveau de méthylation : la méthylation de la lysine 4 de l'histone $\mathrm{H} 3$ (H3K4Me) engendre une conformation de chromatine transcriptionnelle active alors que la méthylation de la lysine 9 de l'histone H3 (H3K9Me) est associée à un état répressif.

De manière générale, ces deux types de modifications sont antagonistes, et la désacétylation des lysines doit précéder leur méthylation. Cet antagonisme entraîne une modification dynamique de l'état chromatidien avec, pour une région donnée, passage d'un état d'hétérochromatine (où les histones $\mathrm{H} 3$ sont désacétylées et méthylées et les gènes sont généralement non exprimés) à un état d'euchromatine (où les histones $\mathrm{H} 3$ sont acétylées et déméthylées et les gènes sont en général exprimés) et vice versa. Les modifications des extrémités des histones jouent donc le rôle de «marques» épigénétiques qui entraînent le recrutement de différentes classes de protéines, puisque les lysines acétylées ou méthylées sont reconnues par des domaines protéiques différents. De ce fait, ces modifications forment un véritable code, "le code des histones», modulant l'architecture de la chromatine et définissant des régions de régulation de l'expression des gènes (Strahl et Allis 2000). Ce code des histones participe à l'orchestration d'un ensemble d'interactions protéines-protéines-ADN sous-tendant le contrôle de l'expression des gènes. Ses composants sont largement conservés à travers l'évolution. Cependant, l'étude de leurs distributions sub-nucléaire et chromosomique suggère que leurs fonctions aient pu évoluer de manière divergente en fonction des organismes.

\section{3 / Les protéines Polycomb et Trithorax}

Les protéines du groupe Polycomb (PcG pour Polycomb Group) et les protéines du groupe Trithorax (TrxG) ont été initialement identifiées chez la drosophile comme régulateurs des gènes homéotiques Hox, un groupe de gènes codant pour des facteurs de transcription spécifiant l'identité cellulaire tout au long de l'axe antério-postérieur. Des études ont permis d'identifier les séquences consensus permettant la fixation de ces protéines. Se fixant sur des éléments de réponse $P R E$ et TRE, médiateurs d'un état silencieux pour les PcG ou actif pour les TrxG, de la chromatine, ces complexes protéiques constituent la mémoire de ces régulations au cours des divisions cellulaires et ainsi d'en contrôler l'héritabilité épigénétique (Schwartz et Pirrotta 2007).

Chez les vertébrés, ces protéines régulent aussi les gènes Hox mais sont en plus impliquées à la fois dans la régulation de la prolifération cellulaire (Martinez et Cavalli 2006), dans l'identité des cellules souches (Sparmann et van Lohuizen 2006), dans les processus de l'empreinte parentale et dans l'inactivation du chromosome $\mathrm{X}$ chez la femelle.

\section{4 / Les ARN non-codants}

Dans le monde des ARN, les ARN non-codants prennent une place de plus en plus importante. Par définition, ils ne codent pour aucune protéine et leurs fonctions sont diverses (figure 2, Costa 2008, Mattick 2009). Depuis longtemps, ARN ribosomiques (rRNA) et ARN transfert (tRNA) étaient connus pour leur implication dans la traduction. Plus récemment, des ARN non-codants de grande taille (long ncRNA) ont été décrits comme régulateurs de l'expression de grands domaines chromosomiques (ex : Xist dans l'inactivation de l'X chez la femelle ; AIR ou LIT1 régulateurs de l'empreinte parentale). D'autres sont impliqués dans la maturation des ARN : les petits ARN nucléaires (SnRNA pour small nuclear RNA) interviennent dans l'épissage des ARNm et les petits ARN nucléolaires (snoRNA pour small nucleolar RNA), localisés dans le nucléole, permettent la maturation des ARNr. Découverts dans les années 90, les ARN interférants (siRNA pour small interfering $R N A$ ) contribuent à la dégradation des ARNm et les micro ARN (miRNA) constituent un groupe d'importants régulateurs de la traduction. Un exemple en est donné par deux récentes études montrant que le miRNA miR-302 est capable à lui seul de reprogrammer des cellules en cellules embryonnaires souches pluripotentes, à la manière des facteurs de transcription Oct4, Sox 2 et Nanog (Barroso-del Jesus et al 2009). Enfin, des ARN interagissent avec les protéines PIWI, responsables notamment de la stabilité du taux de divisions cellulaires dans la lignée germinale et très conservées au cours de l'évolution des

Figure 2. Présentation du monde des ARN dans la cellule eucaryote (d'après Gabory 2008).

\section{Le monde des ARN}

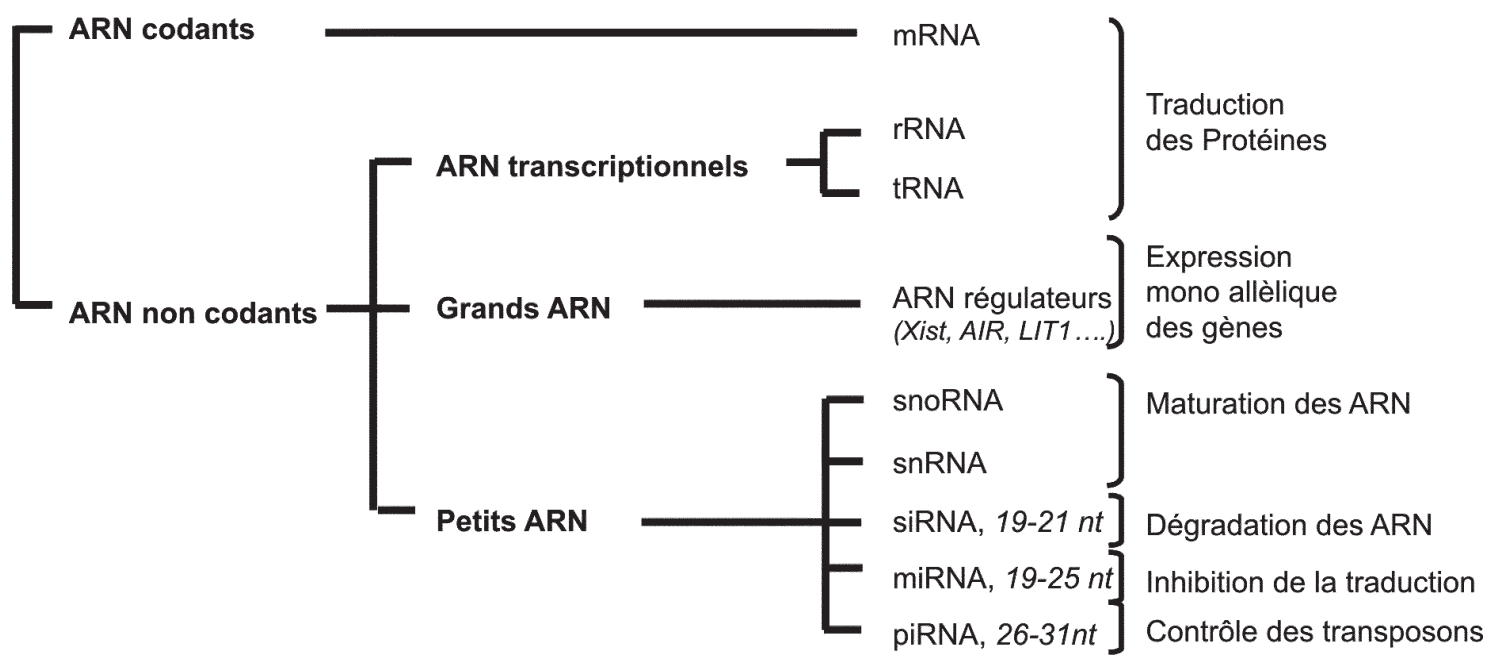


espèces. Ces piRNA (pour piwi interacting $R N A$ ) sont spécialisés dans la protection des génomes contre les éléments transposables et de récentes études proposent même une coopération entre les voies liées aux piRNA et la méthylation de l'ADN dans la lignée germinale de mammifères (Aravin et Bourc'his 2008).

La contribution des ARN noncodants, en particulier des petits ARNs, dans la transmission des marques épigénétiques de génération en génération a été élégamment mise en évidence chez les plantes (Mallory et Vaucheret 2006, Molinier et al 2006) où le processus de paramutation, défini comme le transfert à travers la méiose d'un état épigénétique acquis, implique des petits ARN (Suter et Martin 2010).

\section{3 / Flexibilité et stabilité des marques épigénétiques}

Les marques épigénétiques que nous venons de présenter contribuent à la fois à l'engagement de la cellule vers un type cellulaire bien défini et au maintien de son identité au cours du processus de différenciation. Les dérégulations épigénétiques peuvent aboutir à de graves pathologies illustrées par divers syndromes chez l'Homme ou à des phénotypes très particuliers chez les animaux domestiques.

Voyons ici quelles sont les évidences démontrant la dualité des marques épigénétiques : flexibilité et stabilité.

\section{1 / Flexibilité au cours de la différenciation cellulaire}

Par flexibilité, nous entendons ici la réversibilité et apposition de nouvelles marques. La nécessité de marques épigénétiques flexibles, dont les effets se manifesteront sur le long terme, est bien mise en évidence au début du développement embryonnaire et fœtal (Reik 2007).

Juste après la fécondation, les patrimoines génétiques maternel et paternel, encore séparés à l'état de pronoyaux au sein du cytoplasme de l'ovule, subissent des modifications épigénétiques profondes (figure 3) qui vont permettre d'exprimer très rapidement les gènes responsables du programme de développement embryonnaire. L'étape de l'activation du génome nouvellement formé est à cet égard cruciale. Elle est associée à une déméthylation des génomes (paternel et maternel complète ou partielle selon les espèces considérées), à une méthylation de l'histone $\mathrm{H} 3$ sur les résidus lysine 27 et 9 plutôt associée à une répression transcriptionnelle et à l'intervention des protéines Polycomb. L'évolution de ces marques, en fonction du pronucléus ou du stade du développement, est représentative de la flexibilité des processus épigénétiques nécessaires à l'identité ultérieure des cellules (Beaujean et al 2005).

Plus tard, à partir du stade 4 cellules, une distribution asymétrique des marques épigénétiques précède les modifications d'activité des gènes (Torres-Padilla 2008). Elle conduit les cellules issues des deux premières divisions de l'œuf à s'engager dans les

Figure 3. L'évolution du profil de plusieurs marques épigénétiques au tout début du développement de l'embryon de souris est maintenant bien connue grâce aux travaux de plusieurs laboratoires dont en France le laboratoire de Biologie du développement et Reproduction (INRA, Jouy-en-Josas ; Adenot et al 1991, Beaujean et al 2005).

Les embryons sont collectés in vivo chez la souris de la fécondation au stade blastocyste. Les embryons sont fixés et analysés par immunohistochimie en utilisant différents anticorps.

\section{A. Chronologie de la fécondation à la première mitose.}

Juste après la fécondation, pronucléus paternel $(P)$ et maternel $(M)$ sont identifiables ; leur évolution au cours du temps permet de caractériser des stades particuliers de développement (de PN1 à PN5).

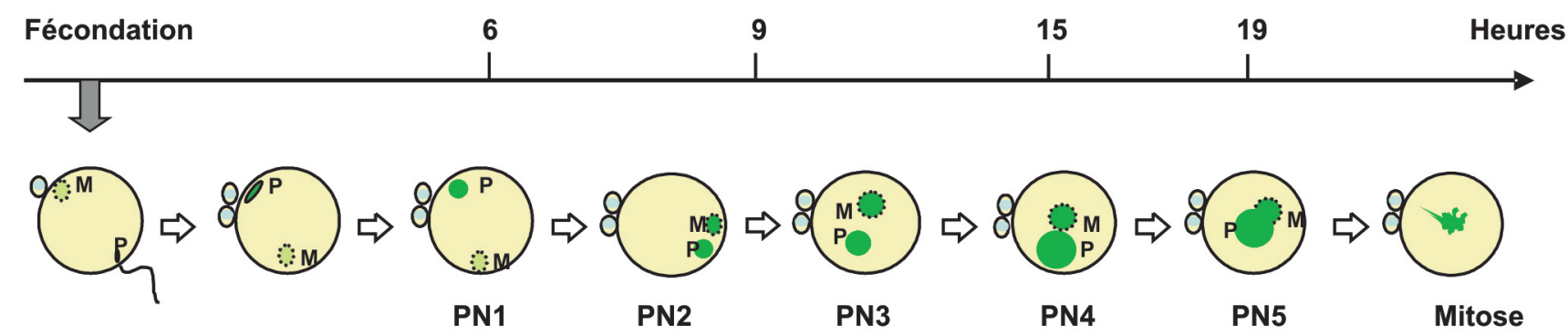

\section{B. Suivi de l'acétylation de la lysine 5 de l'histone H4.}

L'évolution de l'acétylation de la lysine 5 sur l'histone $\mathrm{H} 4$ a été suivie à ces différents stades. Chez la souris, aucune acétylation de la lysine 5 de l'histone $\mathrm{H} 4$ n'est détectée avant la fécondation ni dans le spermatozoïde ni dans l'ovocyte mature. Dès la pénétration du spermatozoïde, un marquage apparaît et s'amplifie avec la décompaction du pronucléus paternel. Peu à peu, le marquage apparaît aussi dans le pronucléus maternel. Au moment de la première mitose, les marquages dans les deux pronucléus sont équivalents.
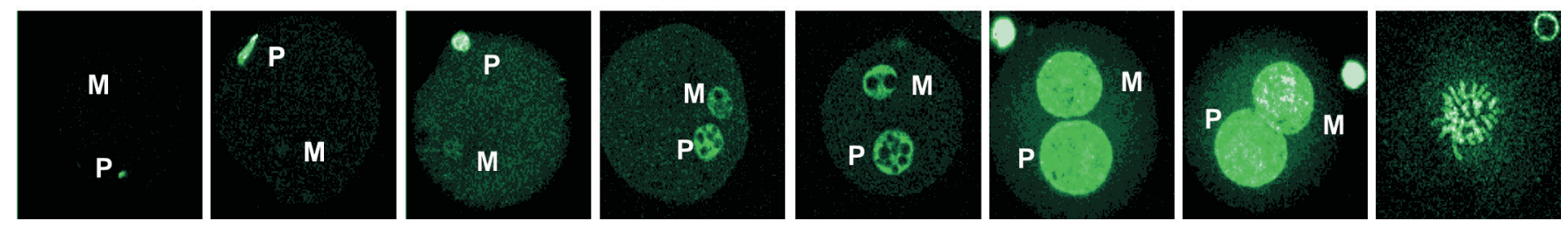

$\mathrm{PN}=$ Pronucléus $; \mathrm{M}=$ Maternel $; \mathrm{P}=$ Paternel 


\section{Suivi de la méthylation sur les lysines 9 et 27 de l'histone H3 et de la méthylation au cours du développement.}

Juste après la fécondation, la lysine 9 de l'histone H3 est majoritairement tri-méthylée (H3K9me3) dans le génome maternel. Dès le stade 2 cellules, le marquage $\mathrm{H} 3 \mathrm{~K} 9 \mathrm{me} 3$ est d'intensité équivalente dans les deux génomes parentaux et est maintenu par la suite dans tous les blastomères sous forme de ponctuations correspondant aux régions d'hétérochromatine condensée. La marque H3K9me3 est aussi associée à la répression transcriptionnelle des gènes.

Le marquage H3K27me1 (lysine 27 de l'histone 3) est quant à lui distribué uniformément dans l'ensemble des noyaux et signe une activation transcriptionnelle.

Chez la souris, la méthylation de l'ADN (en vert) des noyaux parentaux se perd avec une déméthylation active du noyau paternel et passive du noyau maternel. Au stade blastocyste, les cellules de la masse interne (ICM) présentent un plus fort taux de méthylation que les cellules du trophectoderme (TE). Les noyaux cellulaires sont marqués en présence d'lodure de propidium (rouge).

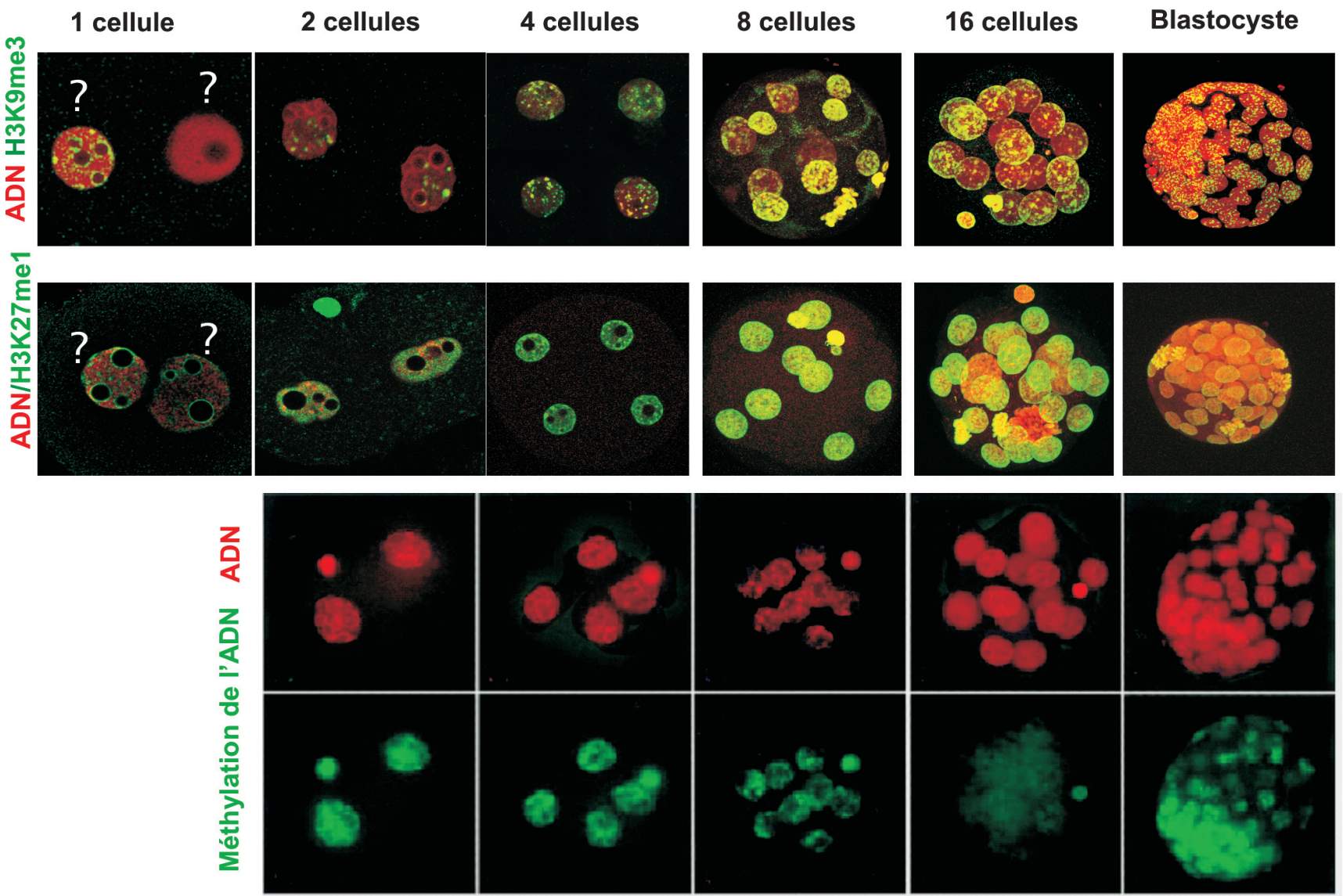

choix décisifs qui dicteront leur devenir: alors que les cellules placées au cœur de la petite masse embryonnaire en développement (la masse cellulaire interne) restent encore à l'état indifférencié, celles qui se retrouvent en périphérie formeront le premier épithélium de l'organisme (le trophectoderme) qui participera aux tissus extraembryonnaires destinés à établir les premiers contacts cellulaires avec l'organisme maternel (figure 4).

Ces deux exemples montrent bien que les changements dans le patron d'expression des gènes sont orchestrés par des modifications épigénétiques et que celles-ci interviennent très tôt au début de l'embryogenèse. Leur rôle est aussi important plus tard, lors de la différenciation des cellules de la masse cellulaire interne qui précède la morphogenèse.
Les expériences de transfert de noyaux somatiques dans des ovules énucléés (clonage, Vignon et al 2008) ou encore les récents travaux démontrant que des cellules banales comme des fibroblastes peuvent, sous certaines conditions de culture être, conduites à redevenir des cellules pluripotentes (cellules iPS, Takahashi et Yamanaka 2006), montrent bien que ces marques épigénétiques peuvent être réversibles et que le micro-environnement du noyau est essentiel à la reprogrammation des activités cellulaires. Ces données de la recherche ont modifié la représentation que nous nous faisions encore récemment de la plasticité de fonctionnement du génome. Mais les taux de succès du clonage sont faibles et l'induction en culture du caractère pluripotent à partir d'une population de cellules différenciées n'est obtenue que pour moins de $1 \%$ d'entre elles. En outre la complexité des modifications épigénétiques augmente rapidement avec le développement et leur reprogrammation reste le plus souvent partielle : les marques épigénétiques forment assez tôt au cours de l'embryogenèse, une barrière épigénétique dont le franchissement conditionnera les caractéristiques morphologiques de l'embryon, puis celles du fœtus (Hayashi et al 2008).

\section{2 / Stabilité des marques épi- génétiques : l'exemple des gènes à empreinte parentale}

Chez les mammifères, les génomes parentaux ne sont pas fonctionnellement équivalents mais porteurs d'informations différentes indispensables au développement de l'organisme (figure 5, Gabory et Dandolo 2005). L'empreinte parentale correspond à 
Figure 4. Le développement d'un organisme du stade zygote à l'adulte est une succession de phases de reprogrammation et de différenciation.

Les changements dans l'expression des gènes sont dictés par des facteurs de transcription et des modifications épigénétiques. Cela impose une mémoire cellulaire héritable orchestrant un déterminisme cellulaire vers un lignage ou un autre. La première phase de différenciation concerne le stade blastocyste avec la mise en place de deux lignages différents, le trophectoderme (TE) et la masse cellulaire interne (ICM) qui donneront respectivement les annexes extra-embryonnaires et l'embryon. La méthylation de l'ADN et les modifications post-traductionnelles des histones présentent une asymétrie entre ICM et TE. II est aujourd'hui possible chez la souris de proposer un modèle de régulations géniques impliqué dans cette première phase de différenciation. Au cours de la transition entre morula et blastocyste, une méthylation de novo est préférentiellement établie dans l'ICM. Dans le TE, le promoteur du facteur de transcription Elf5 est non méthylé et transcriptionnellement actif de par la possibilité de la fixation d'un facteur de transcription TE-spécifique, Cdx2. Le facteur Elf5 renforce alors un feedback positif activant à son tour le promoteur du gène $C d x 2$. La transcription de Nanog, Sox2 et Oct4 est alors inhibée, l'ensemble de ces régulations permettant le maintien d'un patron d'expression génique spécifique de l'identité TE.

Dans I'ICM, la méthylation du promoteur du gène Elf5 en inhibe la transcription et bloque la mise en route de la boucle de régulation TE-spécifique. Le promoteur du gène $C d x 2$ est quant à lui enrichi en marques épigénétiques du code des histones répressives le rendant silencieux. En revanche, les promoteurs des gènes Nanog, Sox 2 et Oct4 sont enrichis en marques activatrices permettant une expression massive de ces gènes de la pluripotence.

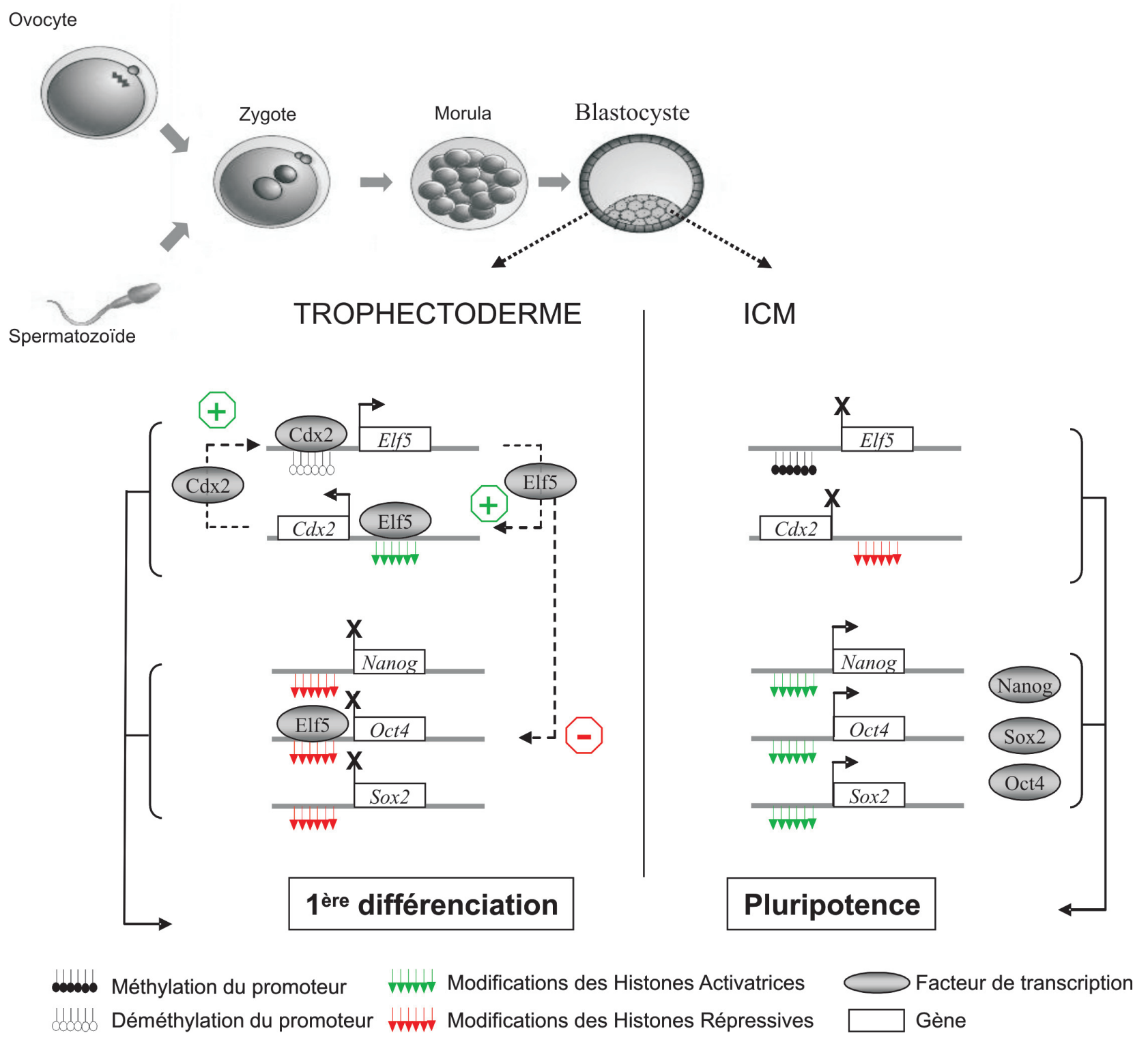

une apposition de marques épigénétiques au cours de la gamétogenèse, marques différentes chez le mâle et la femelle, transmissibles au cours des mitoses après la fécondation conférant une inactivation de l'allèle paternel ou maternel (figure 6). Ce silence trans- criptionnel est opérationnel de manière complète ou partielle, dans certains tissus ou à certains stades du développement.

En isolant, par croisements chez la souris, les individus issus de transloca- tions Robertsoniennes (recombinaison par fusion centriques à la méiose de deux chromosomes acrocentriques), une carte des principales régions chromosomiques non équivalentes en fonction de leur origine, paternelle ou maternelle, a été établie ainsi qu'une liste d'une cen- 
Figure 5. Les expériences visant la reconstitution d'embryons diploïdes gynogénotes et androgénotes menées dans les années 1980 ont permis d'établir la non équivalence des génomes parentaux (Surani et al 1984, McGrath et Solter 1984).

Ainsi, des zygotes sont collectés chez la souris juste après la fécondation ; un des pronucléus est ôté et remplacé. Deux pronucléus d'origine maternelle sont placés dans les embryons gynogénotes, deux pronucléus d'origine paternelle dans les embryons androgénotes. Après implantation dans des femelles pseudogravides, les embryons gynogénotes et androgénotes dégénèrent mais présentent des phénotypes différents. Les embryons gynogénotes accèdent au stade 25 somites et présentent des annexes extra-embryonnaires atrophiées. Les embryons androgénotes ne dépassent pas le stade 9 somites, ont un développement retardé et pourtant présentent des annexes extra-embryonnaires très développées. La présence des génomes maternel et paternel est donc indispensable au bon développement fœto-placentaire.

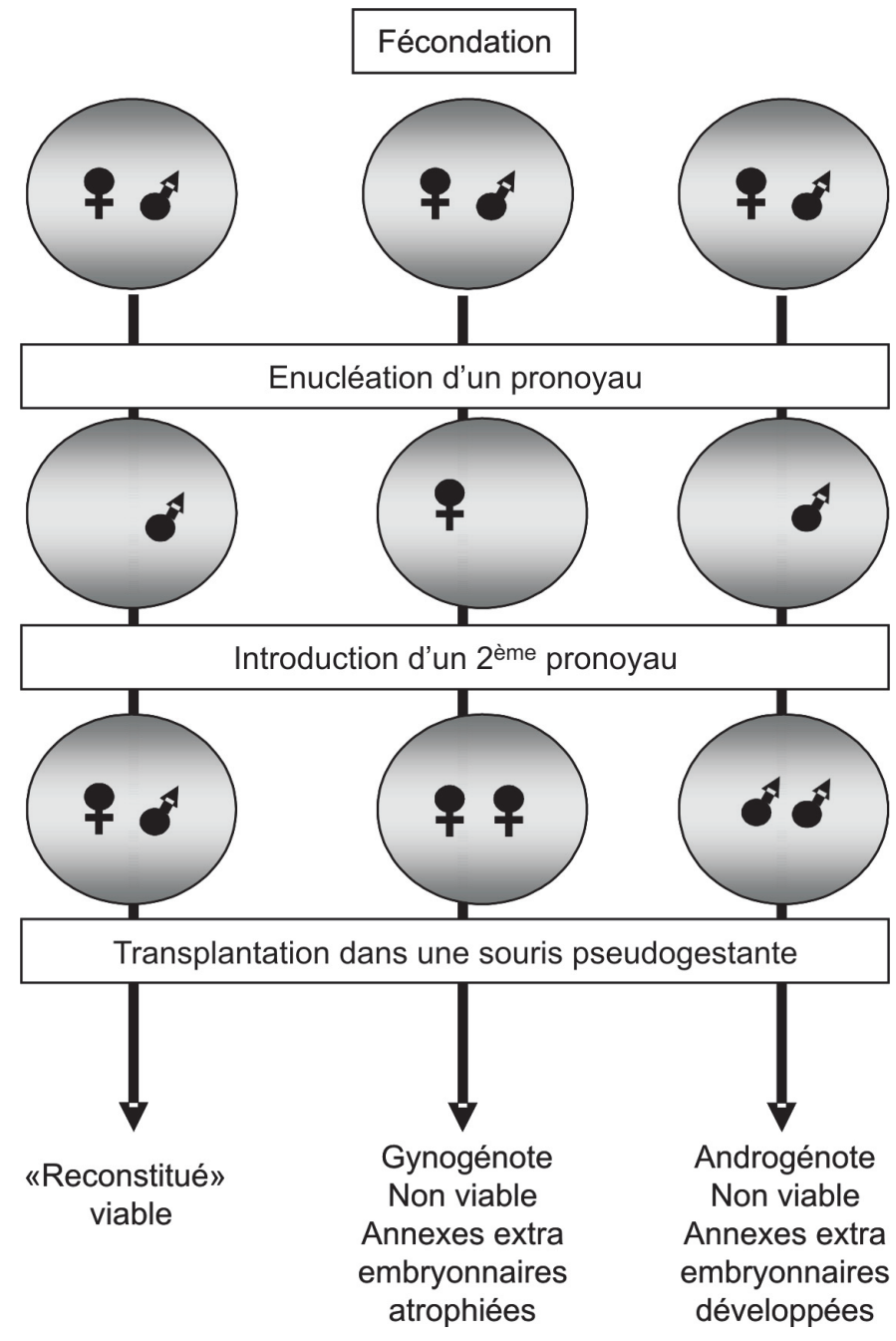

taine de gènes, pouvant prétendre à l'appellation de gènes soumis à l'empreinte parentale (http://www.har.mrc.ac.uk/ research/genomic imprinting, Cattanach et al 2004). Même si cette liste n'est pas exhaustive (les analyses in silico donne une prédiction d'environ 600 gènes, Luedi et al 2007), les gènes soumis à empreinte et par définition à expression allèle spécifique, ne représentent qu'une fraction faible du génome. Mais les processus épigénétiques impliqués dans leur régulation pourraient concerner un nombre bien plus important de gènes : en effet une expression monoallélique aléa- descendance vigoureuse (figure 7). En miroir, les gènes d'expression maternelle codent des protéines clairement associées à une modération voire une inhibition de ces fonctions trophiques placentaires, garante non seulement de la gestation en cours, mais aussi des gestations à venir et de la santé de la mère. Cette opposition entre deux fonctions que d'aucuns se plaisent à représenter comme un «conflit parental», fait appel à des mécanismes de marques épigénétiques différentielles selon la composante parentale du génome. Elle peut être considérée comme le reflet d'une différence fondamentale dans la stratégie de reproduction des individus mâles et femelles.

b) Les marques épigénétiques de l'empreinte parentale et leurs altérations

La méthylation allèle-spécifique des centres d'empreinte (pour Imprinting Center Region) ou DMR (pour Differentially Methylated Regions) concerne des régions inter-géniques et des régions promotrices. La méthylation allélique spécifique de ces régions est responsable de l'empreinte de tout un locus de par la fixation de facteurs de type «silencers» (répresseurs), de type «enhancer» (activateurs) ou encore de type «insulateurs» (isolateurs).

Si nous présentons ci-dessous plus en détail les mécanismes épigénétiques qui régulent l'activité des gènes à ce locus chez la souris, c'est d'abord parce qu'il a pu être démontré que leurs altérations peuvent conduire occasionnellement à des phénotypes d'intérêt chez des mammifères d'élevage. Mais c'est aussi pour montrer que ces mécanismes deviennent accessibles à des analyses moléculaires très fines. C'est un point important. En effet, les phénotypes à empreinte parentale qui dépendent du sens du croisement, c'est-à-dire de l'utilisation de femelles ou de mâles porteurs de l'altération, peuvent être (relativement) facilement décelés et les modifications épigénétiques sous-jacentes décryptées malgré leur complexité moléculaire. La situation est très différente pour les altérations épigénétiques qui n'impliquent pas l'empreinte parentale. Disposer de données moléculaires pour le criblage épigénétique d'animaux manifestant des phénotypes particuliers (phénotypes extrêmes) pourrait révéler une fréquence inattendue d'altérations qu'il deviendrait alors important de pouvoir suivre sur plusieurs générations.

Le locus $\operatorname{Ig} 2 / \mathrm{H} 19$, objet de nombreuses études génétiques chez la souris (Lopes et al 2003, figure 8A), est devenu un paradigme de l'empreinte parentale. Les mécanismes moléculaires 
Figure 6. L'empreinte parentale nécessite l'apposition de marques différentielles sur chacun des allèles, maternel et paternel. Au cours du développement fœtal, le génome des cellules germinales primordiales subit un écrasement complet de toutes les marques épigénétiques au moment de la colonisation des futures gonades. En fonction du sexe de l'embryon, spermatogenèse ou ovogenèse démarrent. Ainsi au stade spermatogonie, tous les allèles paternels $(P)$ ont acquis des marques épigénétiques, c'est-àdire avant la naissance de l'individu mâle. Chez la femelle, l'acquisition des marques épigénétiques est plus tardive et s'effectue au cours de la maturation de l'ovocyte. Les marques ainsi différentiellement apposées sont conservées après la fécondation, lues et maintenues dans les cellules somatiques de l'embryon et de ses annexes extra-embryonnaires jusqu'au stade adulte.

\section{Lecture}

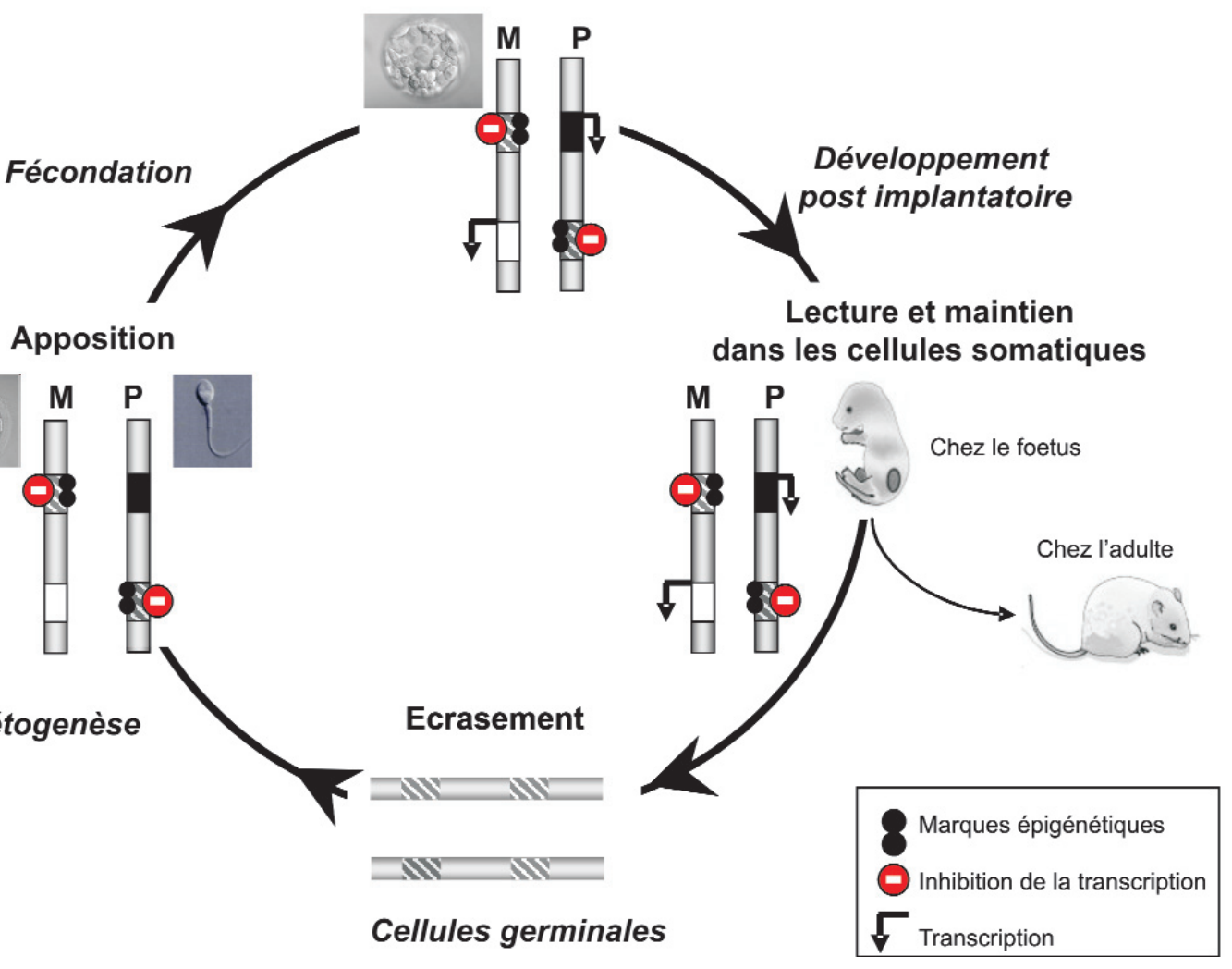

Figure 7. Illustration du concept du «conflit parental».

Les gènes d'expression paternelle (exp $\mathrm{P}$ ) sont favorables au développement fœto-placentaire alors que les gènes d'expression maternelle $(\exp \mathrm{M})$ ont tendance à le modérer. Le gène $Z A C$ (exp $\mathrm{M})$ code un facteur de transcription capable de co-réguler transcriptionnellement les gènes IGF2 (exp $\mathrm{P})$ et $H 19(\exp \mathrm{M})$. Le gène $H 19$ code un ARN non-codant qui semble réguler transcriptionnellement et post transcriptionnellement le gène IGF2. IGF2 et H19 présentent une expression allèlique en miroir régulée épigénétiquement (cf. figure $8 \mathrm{~A}$ et $\mathrm{B}$ ). Le gène IGF2R (exp M) code le récepteur IGF de type 2 c'est-à-dire un récepteur membranaire associé au système des lysosomes et fonctionnant comme un régulateur négatif de la biodisponibilité d'IGF2. Enfin, SLC22a2 (exp M) est un gène qui code pour un transporteur de nutriments qui est directement régulé par IGF2. L'équilibre des forces exercées par ces différents partenaires est garant d'un développement fœto-placentaire harmonieux.

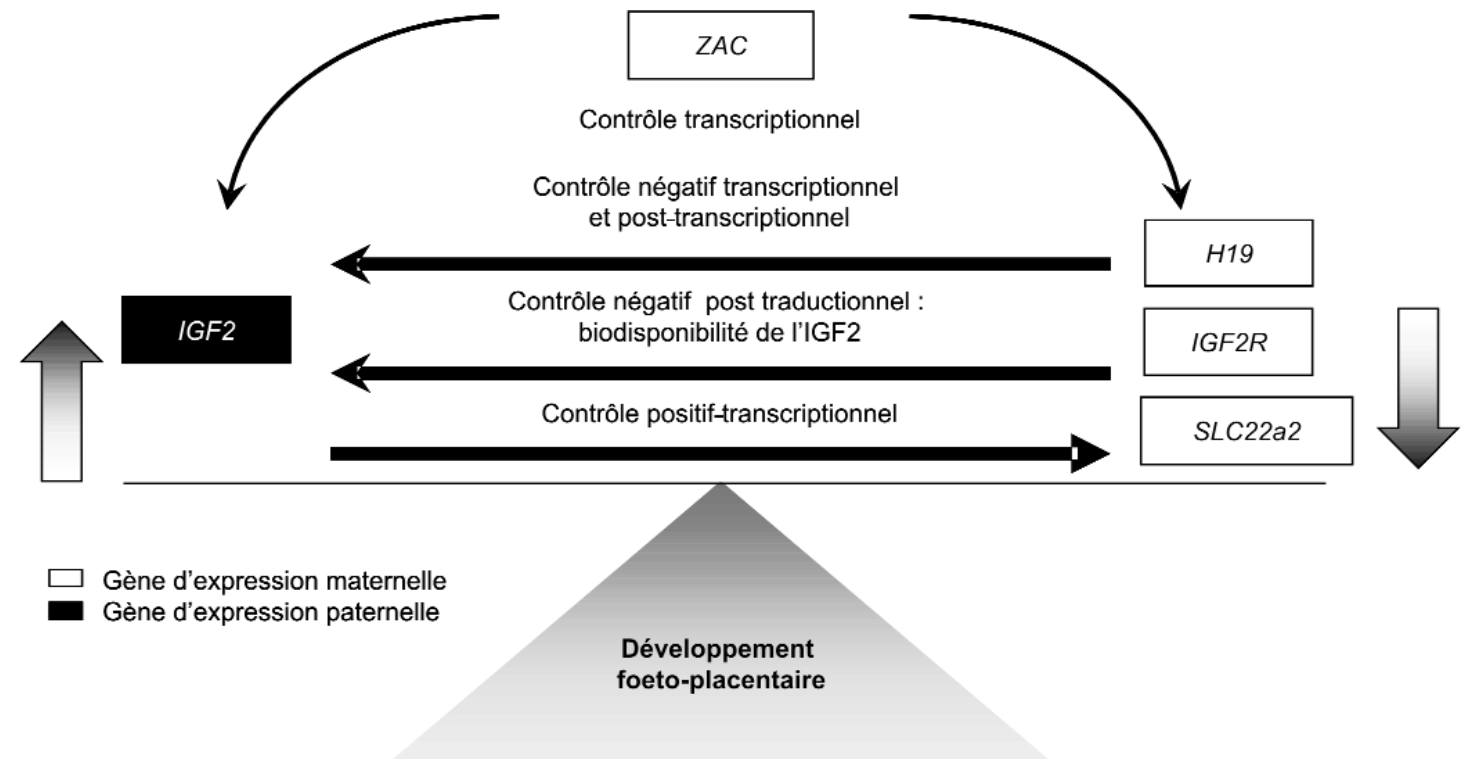


Figure 8. Régulations de l'expression mono-allèlique des gènes lgf2 et H19, chez la souris.

A. Modèle linéaire. Le locus Igf2/H19 met en jeu plusieurs régions différentiellement méthylées (DMR0, DMR1 et DMR2 pour le gène lgf2 et H19 DMR ou centre d'empreinte (ICR) pour le gène H19), des régions stimulatrices ou «enhanceurs» (E) en 3' de $H 19$, des éléments régulateurs activateurs $(\mathrm{A})$ ou inhibiteur $(\mathrm{S})$. Le gène Igf2 peut être transcrit à partir de plusieurs promoteurs (P0, P1, P2, P3) tissu- et stade-spécifiques. Sur l'allèle paternel, la transcription du gène lgf2 est favorisée par l'interaction préférentielle des enhanceurs sur les promoteurs et par l'action d'un élément activateur se fixant sur la DMR2 méthylée. Le gène H19 n'est pas transcrit. Sur l'allèle maternel, la fixation de la protéine CTCF sur l'ICR H19, sert d'insulateur favorisant les interactions de l'enhanceur avec le promoter de $H 19$, les promoteurs du gène lgf2 n'étant plus accessibles.

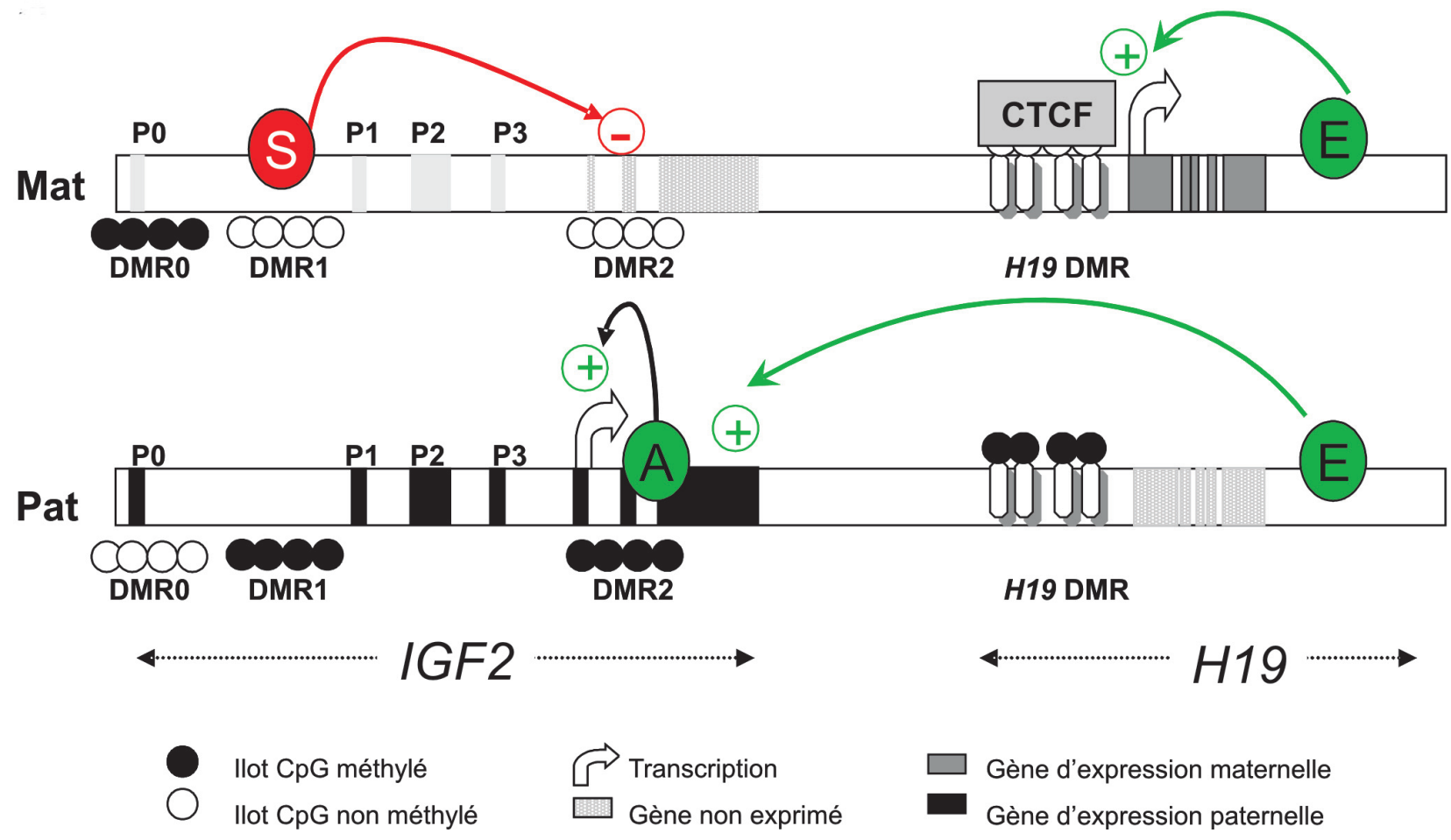

B. Modèle spatial. De récentes expériences de capture de l'architecture de la chromatine ont permis de révéler des interactions physiques entre différentes régions génomiques via des différents facteurs. Sur l'allèle maternel, la fixation du CTCF sur l'ICR non méthylée favorise des interactions avec la DMR1 non méthylée et une région génomique MAR3 aboutissant à la formation d'une boucle de chromatine inactive dans laquelle se trouve le gène IGF2. Sur l'allèle paternel, l'ICR méthylée interagit avec la DMR2 et une région génomique MAR2 fermant cette région de chromatine à la transcription. Un rapprochement physique entre l'enhanceur (E) la polymérase II (Pol II) et les promoteurs du gène IGF2 est alors physiquement possible.
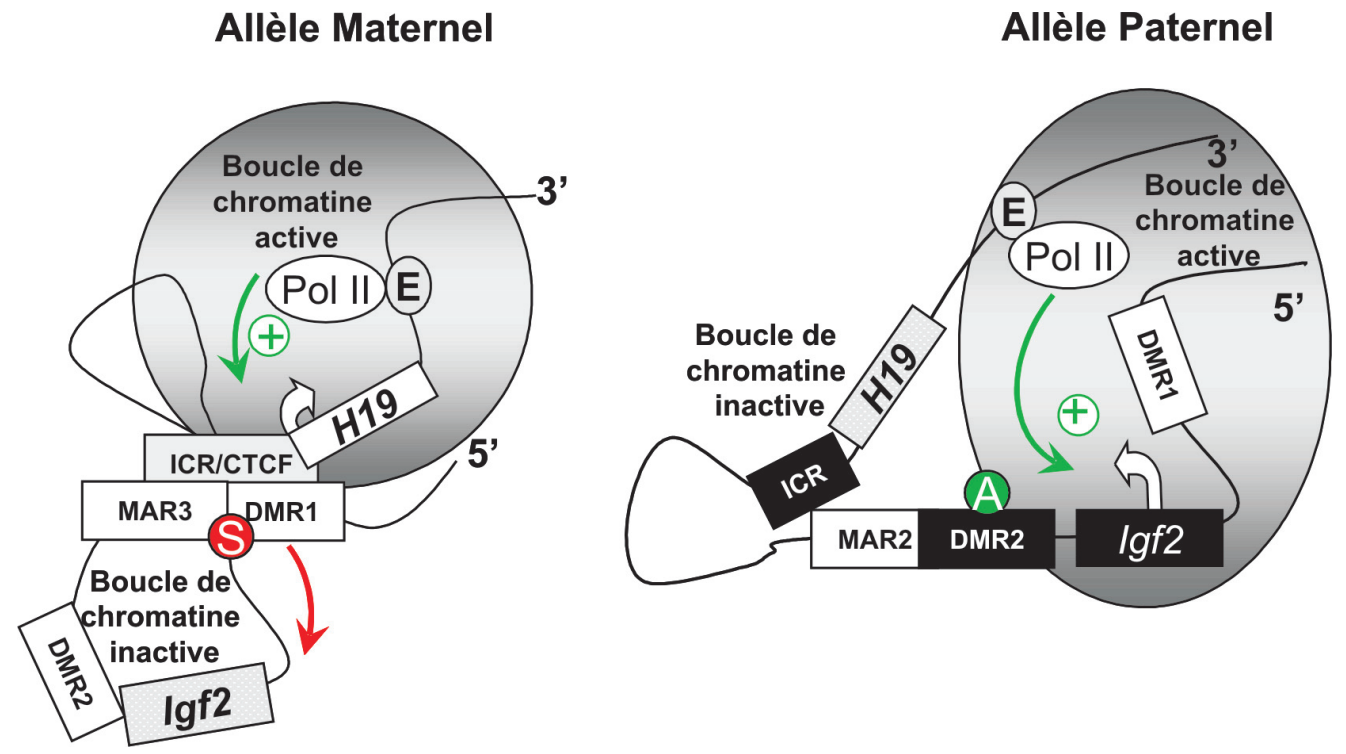
responsables de l'expression mono-allèlique en miroir des gènes $\operatorname{Ig} f 2$ et $H 19$ sont maintenant bien décortiqués. Leurs altérations conduisent généralement à des dérégulations délétères, avec des syndromes pathologiques chez l'Homme (Syndrome de BeckwithWiedeman et de Silver Russel).

Le centre d'empreinte est situé $2 \mathrm{~kb}$ en amont du site d'initiation de la transcription du gène $H 19$ murin. Sur l'allèle maternel, ce centre d'empreinte est non méthylé et fixe une protéine nucléaire en doigt de zinc, le CTCF. CTCF agit comme une véritable barrière physique, favorisant les interactions entre les «enhancers» positionnés en 3' du gène $H 19$ et le promoteur, favorisant une transcription à partir de l'allèle maternel et bloquant toute interaction avec les promoteurs du gène $\operatorname{Ig} f 2$. Sur l'allèle paternel, la méthylation du centre d'empreinte inhibe la fixation de CTCF et libère l'accessibilité des promoteurs d'IGF2 assurant ainsi la transcription de ce gène à partir de l'allèle paternel. La méthylation de l'ADN contrôle donc de manière allèle-spécifique la transcription de deux gènes situés dans un locus de $100 \mathrm{~kb}$, démontrant la possibilité de régulation à distance. De très récentes études ont aussi démontré qu'il était nécessaire d'imaginer une plasticité de la molécule d'ADN caractérisée par des repliements de petites régions chromosomiques. Les contacts physiques entre les différents partenaires/régions en fonction de leur état de méthylation dictent des repliements locaux de la chromatine et la formation de boucles responsables de l'enfermement des gènes dans un silence transcriptionnel (figure 8B). L'architecture locale de la chromatine participe donc activement à la lecture du génome (Murell et al 2004, Qiu et al 2008).

\section{Tableau 2. Historique du locus IGF2 dans l'hypertrophie musculaire chez le porc.}

1999-2000 : Localisation d'un QTL affectant la masse musculaire sur le chromosome 2p1.7, locus synthénique du chromosome $11 \mathrm{p} 15$ humain et du chromosome 7 murin Croisement Large White x Pietrain, Nezer et al (1999) Croisement Sanglier $x$ Large white, Jeon et al (1999) Croisement Landrace $x$ Large White, de Koning et al (2000)

2002 : Implication du gène /GF2 dans le phénotype d'hypermuscularité Amarger et al (2002)

2003 : Identification d'une mutation d'un seul nucléotide $\mathrm{G} \rightarrow$ A dans l'intron 3 du gène /GF2, Van Laere et a/ (2003)

2004 : Identification d'un transcrit /GF2 antisens dont la transcription est modifiée par la mutation, Braunschweig et al (2004)

Chez l'Homme, ce locus est impliqué dans les syndromes de BeckwithWiedemann (BWS) et de Silver Russel (SRS). Les manifestations morphologiques de ces deux syndromes sont en miroir. Pour les BWS, une organomégalie fotale est associée à une hypertrophie placentaire. A contrario, le SRS présente un retard de croissance fotal important associé à une hypotrophie placentaire. Des altérations soit de type génétique unidisomie parentale, soit de type épigénétique aboutissent à une perte de l'empreinte parentale. Cela conduit à une expression bi-allèlique du gène $I G F 2$ ou en miroir à une perte totale d'expression dictant dans les deux cas des perturbations importantes du développement du fotus.

c) Empreinte parentale et caractères phénotypiques complexes en élevage

Les deux exemples ci-dessous démontrent l'importance de la connaissance des régulations épigénétiques et de l'empreinte parentale dans l'héritabilité d'un caractère d'élevage, en l'occurrence la répartition et le développement des masses musculaires valorisables en race à viande.
Chez le porc, il avait été identifié sur le chromosome 2, un QTL paternellement exprimé affectant la masse musculaire et le dépôt de gras (Nezer et al 1999) qui fut restreint ensuite à une région de $250 \mathrm{~kb}$ contenant le locus IGF2-H19 (Nezer et al 2003, Van Laere et al 2003, Braunschweig et al 2004). L'implication du facteur protéique IGF2 dans la myogenèse étant bien connue, le gène $I G F 2$ a fait l'objet d'une attention particulière mais aucune mutation n'a été trouvée dans les régions codantes (Nezer et al 1999). En fait, il est démontré qu'une mutation dans l'intron 3 du gène $I G F 2(3072 \mathrm{G} \rightarrow \mathrm{A})$ inhibe la fixation d'un facteur agissant en trans, spécifique du muscle, fonctionnel seulement après la naissance mais non identifié à ce jour. Ceci a pour résultat, que l'animal qui hérite de son père la mutation $(3072 \mathrm{G} \rightarrow \mathrm{A})$ a trois fois plus d'ARNm IGF2 dans ses muscles ce qui en augmente le développement et limite le dépôt de graisse (tableau 2).

L'histoire du phénotype «Callipyge» chez le mouton démarre en 1983 par la naissance d'un agneau porteur d'une hypertrophie musculaire des mus-

\section{Tableau 3. Le locus Callipyge en quelques dates.}

1983 : Naissance d'un agneau avec une hypertrophie musculaire

1994 : Localisation chromosomique du locus Callipyge chez l'ovin sur la partie télomérique du Chromosome 18 , région synthénique du chromosome 14q32 chez l'Homme et du chromosome 12 chez la souris. Cockett et al (1994)

1996 : Mise en évidence d'une transmission non mendélienne du phénotype Callipyge. Seule une transmission paternelle de la mutation conduit à ce phénotype. Cockett et al (1996)

2001 : Identification de 6 gènes soumis à l'empreinte parentale au sein du locus Callipyge (250 kb) et mise en évidence d'une régulation coordonnée de leur expression sans perturbation de l'empreinte. Charlier et al (2001b), (2001a)

2002 : Identification de la mutation d'un seul nucléotide $\mathrm{A} \rightarrow \mathrm{G}$ causant le phénotype Callipyge. Freking et al (2002)

2006 : Identification d'un transcrit CLPG1, dont l'expression est mono allélique chez l'adulte et strictement liée à la présence de la mutation sur l'allèle exprimé. Murphy et al (2006)

2006 : Identification d'un réseau de gènes dont l'expression contribue à l'hypertrophie chez les ovins callipyge. Vuocolo et al (2006)

2010 : Identification en utilisant des approches immunologiques et de spectrométrie de masse, d'une protéine PEG11 uniquement présente dans les extraits de muscle adulte Callipyge. Byrne Ket al (2010) 
Figure 9.

A. Représentation schématique du locus DLK1/GTL2 chez l'ovin.

Ce locus est situé sur le chromosome 18 chez l'ovin, synthénique du chromosome 12 chez la souris. Chez l'ovin comme chez la souris, Begain, DLK1, DAT, RTL1/PEG11 et DIO3 sont exprimés à partir de l'allèle paternel et GTL2/MEG3, MEG8 et l'antisens AS RTL1 à partir de l'allèle maternel. CLPG a normalement une expression bi-allèlique. Les flèches indiquent le sens de transcription des gènes.
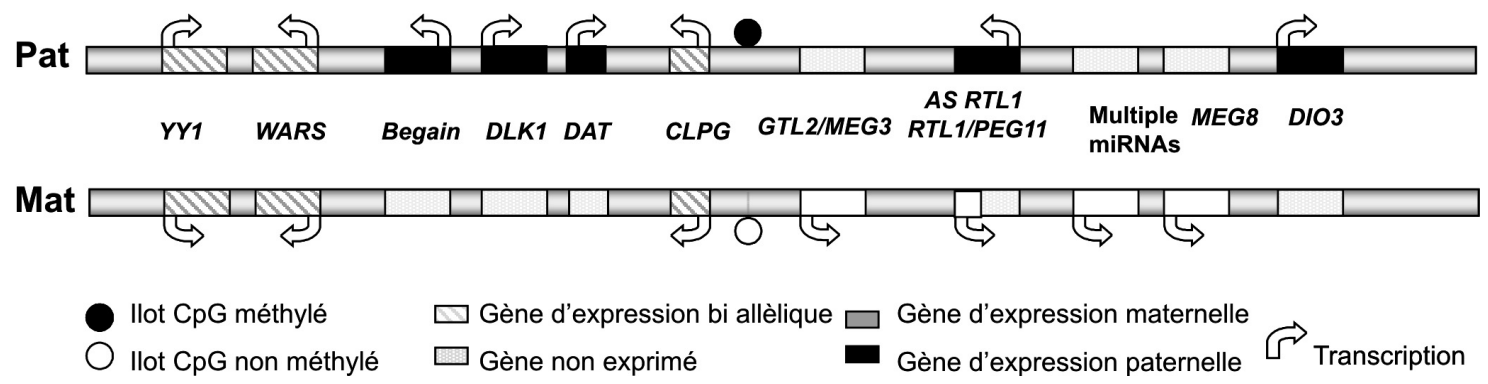

\section{B. Modèle de régulation de l'expression des gènes impliqués dans le phénotype Callipyge.}

Dans le muscle squelettique postnatal normal (génotype Mat ${ }^{A} / P{ }^{A}$ ), GTL2/MEG3, ARN non-codant, est exprimé à partir de l'allèle maternel et inhibe en cis l'expression maternelle de DLK1. DLK1, exprimé très faiblement et uniquement à partir de l'allèle paternel, code une protéine trans-membranaire de la famille NOTCH/DELTA. CLPG1, est exprimé de manière bi-allélique et les deux allèles sont porteurs d'ilots $\mathrm{CpG}$ méthylés.

Quand la mutation, dont la position est indiquée par un triangle noir, est portée par l'allèle maternel (génotype Mat $\mathrm{G} / \mathrm{Pat} A$ ), l'expression de GTL2 et de MEG8 augmente fortement et l'expression de DLK1 diminue, suggérant une régulation négative en trans. CLPG1 est alors exprimé de manière mono-allélique à partir de l'allèle maternel du fait d'une déméthylation partielle de l'ilot $\mathrm{CpG}$ situé en amont du site de transcription. Aucune altération du phénotype n'est constatée.

Quand la mutation est portée par l'allèle paternel (génotype Mat ${ }^{A} / \mathrm{Pat}^{\mathrm{G}}$ ), les animaux sont tous de phénotype «Callipyge». La mutation entraine une surexpression de DLK1 et PEG11, et une augmentation limitée de GTL2 et MEG8. CLPG1 est alors exprimé à partir de l'allèle paternel qui présente une hypométhylation.

Chez les individus homozygotes pour la mutation, (génotype $M a t G / P a t G)$, les effets sur l'allèle maternel sont équivalents à ceux observés pour les porteurs hétérozygotes (génotype $M a t^{G} / P a t^{A}$ ), à savoir une surexpression de GTL2 et de MEG8. Sur l'allèle paternel, la mutation augmente effectivement l'expression de DLK1 et PEG11, mais cet effet est tempéré par l'inhibition en trans exercée par les fortes quantités de GTL2. CLPG1 est exprimé de manière bi-allèlique du fait de la perte de méthylation sur les deux allèles.

L'expression importante des gènes DLK1 et PEG11 à partir de l'allèle porteur de la mutation est donc toujours associée à une perte de méthylation dans la région intragénique $D L K 1 / G T L 2$. Ces résultats suggèrent que la mutation CLPG1 est responsable d'une relaxation locale de la chromatine permissive favorisant la transcription des gènes du cluster. En absence de cette mutation, dans le muscle squelettique et en postnatal, la chromatine subit certainement une compaction répressive liée à son état de méthylation contrôlant négativement l'expression des gènes du locus. $D L K 1$, de par ses variations d'expression en fonction du génotype, du stade de développement et de type de muscle, est un pertinent candidat comme premier effecteur dans le phénotype d'hypertrophie musculaire. PEG11, codant un gène rétrotransposons-like, présente le même patron d'expression mais son rôle n'est pas connu. II en est de même pour l'ARN non codant CLPG1. Des analyses transcriptomiques ont démontré que 375 transcrits étaient différentiellement exprimés dans le muscle squelettique de phénotype Callipyge versus normal. Le modèle Callipyge est un modèle unique d'étude des dérégulations de l'expression sans modification de l'empreinte, de gènes et d'ARN non codant puisque le phénotype est non létal.
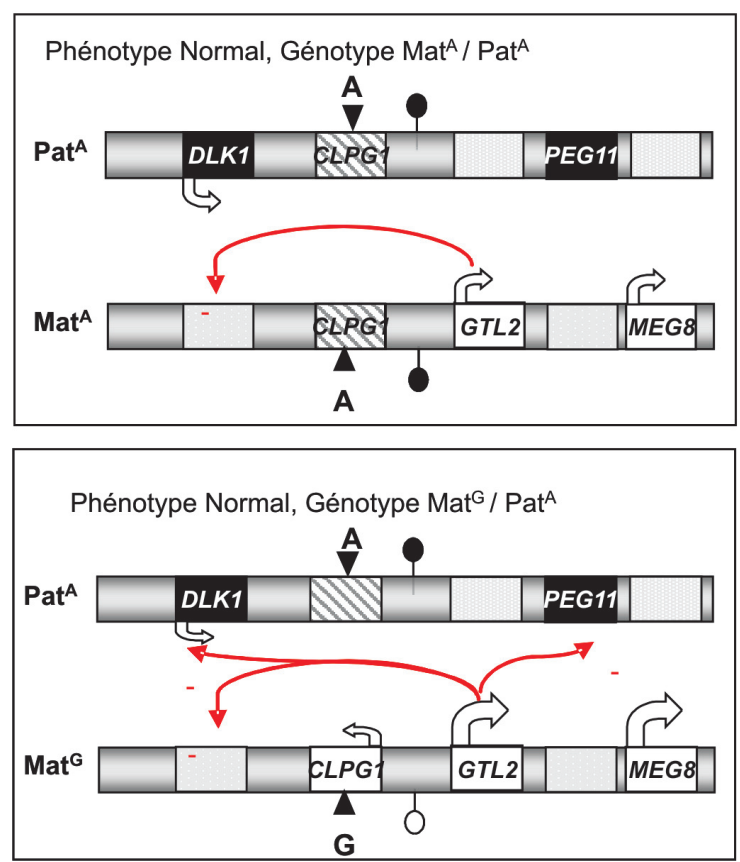
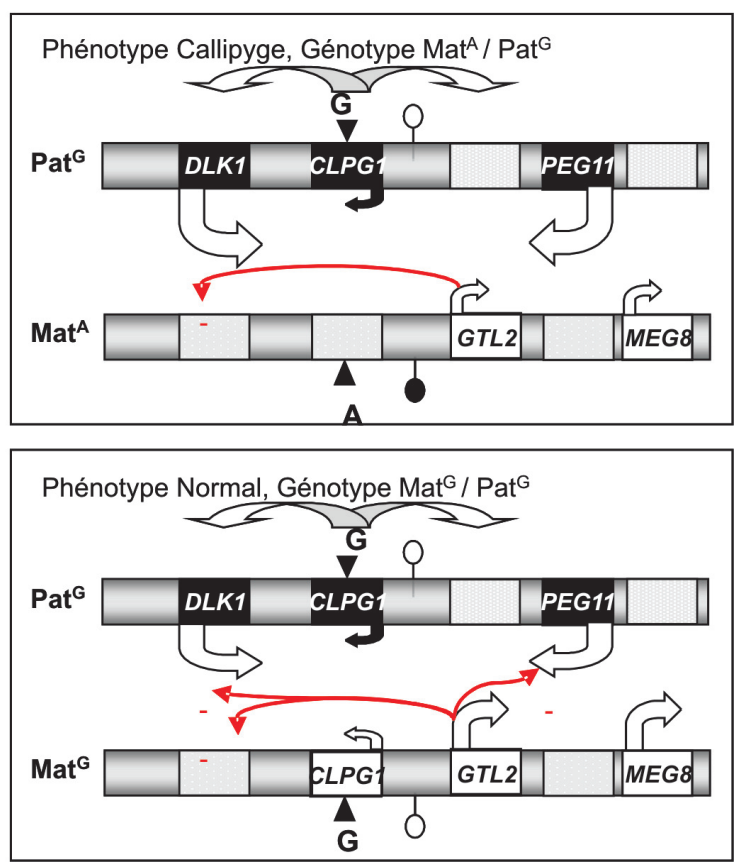
cles postérieurs. Avec beaucoup de perspicacité, Michel Georges et son équipe de l'Université de Liège puis Randy L. Jirtle et son équipe (tableau 3), s'intéressent à ce phénotype et réalisent qu'il ne répond pas à une transmission mendélienne classique. Une patiente enquête moléculaire démontre que le phénotype qu'ils nomment "Callipyge» (littéralement, «belles fesses», en référence à la déesse grecque de l'Amour, Aphrodite Kallipygos) est un modèle de surdominance polaire et correspond à une hypertrophie musculaire avec une augmentation du diamètre et de la proportion des fibres rapides manifeste dès la troisième semaine postnatale. La transmission se fait par un héritage paternel de l'allèle muté (figure 9A et B). En fait, la mutation est située dans une région soumise à l'empreinte parentale ; elle intervient dans la régulation transcriptionnelle du locus, le locus DLK1/GTL2 mais ne modifie pas l'empreinte. Une simple substitution d'un nucléotide, $A \rightarrow G$, au niveau du centre d'empreinte du locus dans la région télomérique du chromosome 18 ovin entraine la dérégulation de plusieurs gènes soumis à l'empreinte parentale. Alors qu'ils sont faiblement exprimés dans les muscles squelettiques, DLK1 et RTL1 sont fortement exprimés lorsque cette mutation est portée par l'allèle paternel. Un nouvel ARN non-codant, CLPG1, est identifié dans la région ; son expression est bi-allèlique chez le fœtus, et devient mono-allèlique dans le muscle adulte (figure 13B). Chez les individus hétérozygotes porteurs de la mutation sur un des allèles, CLPG1 n'est exprimé qu'à partir de l'allèle muté (expression paternelle pour les NormalmatCallipygepat et expression maternelle pour les Callipygemat Normalpat). Cependant, CLPG1 n'est pas exprimé chez les homozygotes (Normalmat Normalpat et

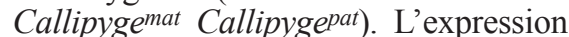
de CLPG1 est exclusivement paternelle. Les gènes $D L K 1$ et $R T L 1$, normalement d'expression eux aussi paternelle sont fortement régulés positivement alors que les gènes d'expression maternelle GTL2 et Rian se trouvent diminués. Récemment, il a été montré que RTL1 est en fait un élément rétro-transposon codant une protéine caractérisée par spectrométrie de masse et uniquement exprimée dans les extraits de muscle Callipyge mais dont la fonction est encore inconnue (Byrne et al 2010).

4 / Des marques épigénétiques à la plasticité phénotypique : réponse ou adaptation aux modifications de l'environnement ?

Les marques épigénétiques permet- tent aux cellules de répondre à leur environnement par un changement dans l'expression de leurs gènes. Nous venons de voir que tout en étant réversibles, elles peuvent propager ces changements de façon stable au cours des divisions des cellules dans un tissu. Selon le type ou l'intensité des variations de l'environnement mais aussi selon la période du développement, ces variations pourront avoir des conséquences sur l'ensemble de l'organisme et affecter son phénotype. Cette plasticité fonctionnelle du vivant est bien une réponse aux modifications de son environnement. Ce type de réponse peut-il perdurer sur plusieurs générations, voire conférer un avantage adaptatif à l'organisme ? Plusieurs travaux tendent à apporter une réponse positive à cette question ; c'est ce qu'illustrent les exemples ci-dessous.

\section{1 / Reine ou ouvrière ? Une question épigénétique chez les abeilles}

Jusqu'à présent, nous savions que devenir reine ou ouvrière chez les abeilles était déterminé par l'alimentation... la gelée royale étant exclusivement réservée aux larves dont le destin était «de monter sur le trône». Bien que reine et ouvrières soient génétiquement identiques, elles diffèrent de manière marquée sur le plan morphologique et physiologique, que ce soit dans leur capacité de reproduction (les ouvrières sont stériles), leur durée de vie ou leur comportement social au sein de la ruche (figure 10). L'alimentation des larves altère le patron d'expression des gènes impliqués dans la trajectoire développementale des individus (Barchuk et al 2007). La démonstration de l'implication de marques épigénétiques dans cette altération a été mise en évidence récemment en injectant un ARN interférant spécifique du gène de la DNA methyltransférase 3 (DNMT3-ARNi) au stade larvaire 1. L'expression de ce gène apparait alors significativement mais transitoirement diminuée au stade larvaire 3 avec comme conséquence majeure, dans $72 \%$ des cas, le développement d'adultes au phénotype de reine. L'analyse de l'état de méthylation d'un autre gène, le gène dynactin p62 connu pour être impliqué dans le développement, montre que chez les larves traitées par le DNMT3-ARNi, le patron de déméthylation de ce gène est similaire à celui des larves futures reines (Kucharski et al 2008, Foret et al 2009)

Empêcher l'expression du gène $D N M T 3$ à un stade précis du développement larvaire ou modifier l'alimentation par apport de gelée royale aboutissent à la même réponse moléculaire (hypométhylation) et favorisent un dévelop- pement plus important de structures telles que le cerveau et les ovaires. Ce résultat montre que la méthylation de l'ADN peut contribuer via l'alimentation à un processus moléculaire fondamental du développement qui, dans le cas de l'abeille conditionnera le devenir social de l'individu !

\section{2 / Reprogrammation epigéné- tique dictée par le comporte- ment maternel}

Chez le rat, il existe des variations stables de comportements maternels au cours des premières semaines de la lactation qui ont pour conséquences des altérations de la résistance au stress chez les jeunes devenus adultes. En effet, les jeunes adultes ayant bénéficié de soins intenses et attentifs (HpLG pour High pup Licking and Grooming) sont moins craintifs et répondent modérément au stress en comparaison avec des jeunes adultes dont les mères présentent un comportement maternel plus distant (LpLG, pour Low pup Licking and Grooming, Cameron et al 2008, McGowan et al 2008). A la génération suivante, les rattes issues de portées LpLG, présentent un comportement maternel LpLG. Cependant, lorsque des adoptions croisées sont pratiquées dès la naissance, les jeunes adultes «nés LpLG» mais élevés par des mères HpLG sont résistants au stress et vice versa.

Ces résultats mettent en évidence une empreinte maternelle pilotant la plasticité du système neuro-endocrinien lié au stress. Récemment, il a été montré (Weaver et al 2004) que dans l'hypocampe, structure cérébrale impliquée dans l'intégration des informations de stress, le gène du récepteur aux glucocorticoïdes est plus méthylé au niveau des régions promotrices, et donc moins exprimé chez les rats LpLG que chez les rats HpLG. Cette différence de méthylation est extrêmement marquée dans les premières semaines de vie, persiste chez les adultes mais est réversible puisque des petits issus de rattes LpLG mais élevés par des rattes HpLG, voient le taux de méthylation de ce gène diminuer. De plus, cette modification épigénétique est associée à une altération de l'acétylation des histones et à une modification de la fixation du facteur de transcription NGFI-A. Toutes ces marques peuvent être reversées par une infusion centrale d'inhibiteur spécifique de la desacétylation.

Ces données démontrent sans ambiguité que l'état épigénétique d'un gène peut être établi selon une programmation issue du comportement et que cet état peut induire une modification du comportement chez les descendants de la première génération. Il peut être complètement reversé si cette program- 
Figure 10. Reine ou ouvrière ? Une question epigénétique chez les abeilles.

A. Développement chez l'abeille de l'œuf, en passant par les trois stades larvaires $(L 1, L 2, L 3)$, le stade de nymphe puis l'apparition de l'adulte.

B. Le dimorphisme de taille entre reine et ouvrières est lié à des fonctions différentes au sein de la ruche et des capacités de reproduction.

C. Schéma expérimental d'inactivation du gène DNMT3. Au cours de développement, l'apport de gelée royale au stade L3 permet le développement d'une reine.

Les injections de RNAi spécifiquement dirigé contre le gène DNMT3 est effectué au stade L1. La répression du gène DNMT3 maximale est observée entre les stades L2 et L3. Dans ce cas, $72 \%$ des larves ainsi injectées, présentent un développement de type «Reine» en prenant la taille et surtout la présence de gonades fonctionnelles comme paramètres de référence.

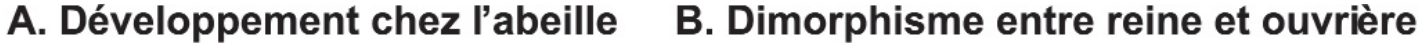
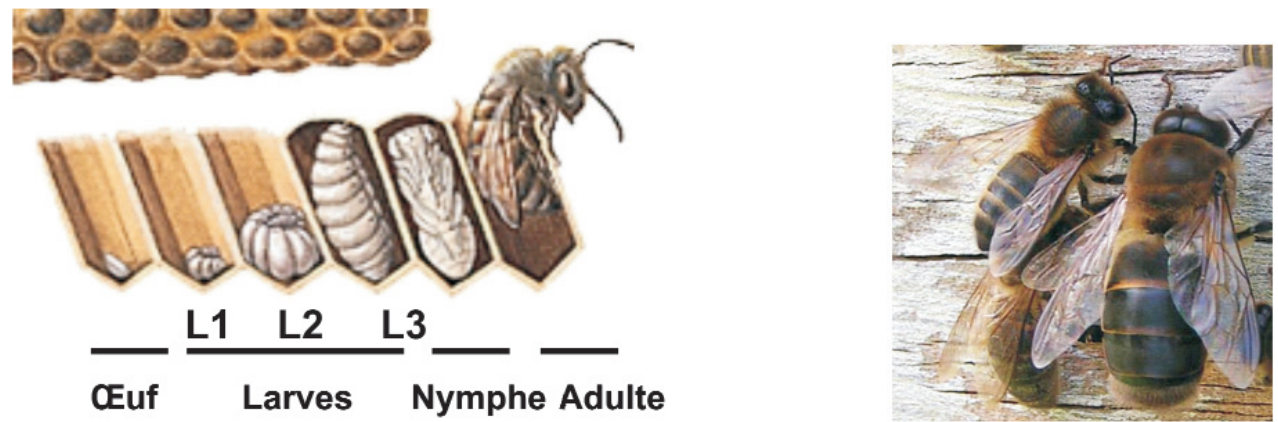

\section{Inhibition de l'expression du gène DNMT3}

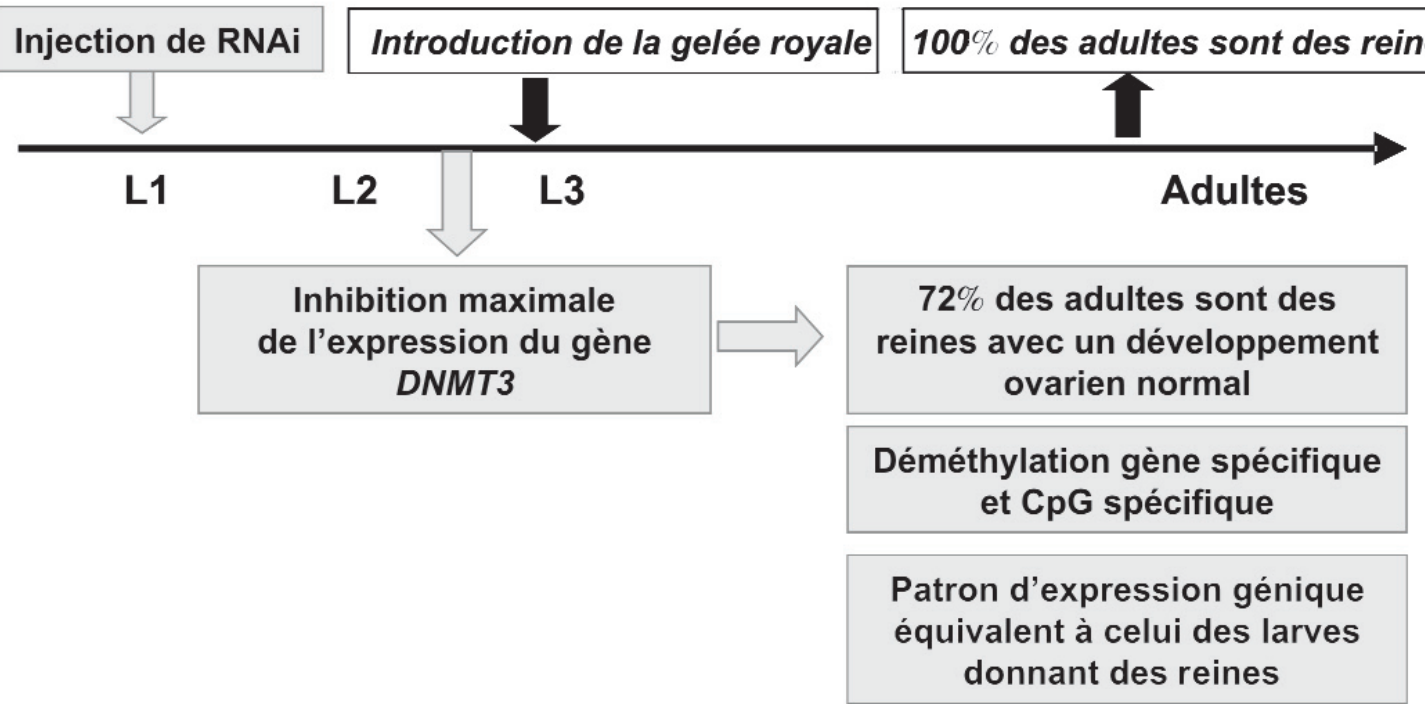

mation «épigénétique» est modifiée (Weaver et al 2004).

Un ensemble intégré de modifications de l'environnement du fœtus, ici les composantes du comportement maternel, peut donc induire une réponse de type adaptative à la génération suivante.

\section{3 / Nutrition et programma- tion fotale}

De nombreuses études épidémiologiques et expérimentales ont démontré une forte influence de l'environnement au cours de la vie intra-utérine sur le développement fœetal et sur la santé du jeune adulte en devenir.
Des arguments s'accumulent pour considérer que le régime alimentaire maternel, la composition corporelle, le style de vie, l'exposition au stress sont d'importants déterminants de la fonction placentaire et du développement fœtal (Gheorghe et al 2010). Le concept selon lequel la nutrition maternelle influence à long terme la santé de la descendance dérive des études épidémiologiques de Barker et coll (Barker 2007). Ces études mettent en relief les effets en Hollande, au cours de la seconde guerre mondiale, de la restriction calorique et de la malnutrition sur le développement fœtal et la prévalence des pathologies cardiovasculaires, du diabète de type 2 , des pathologies pulmonaires et rénales et des troubles de la personnalité dans la descendance (Barker et al 2009).

Chez le rat, il a été démontré une relation entre stress fotal in utéro et restriction alimentaire ou stress émotionnel maternel et prédisposition aux pathologies cardiovasculaires chez l'adulte (Gluckman et al 2008, Jansson et Powell 2007). A l'opposé, des conditions nutritionnelles trop riches (régime "cafétéria» riche en lipides) appliquées chez les mères peuvent induire des perturbations importantes du développement fotal avec un retard de croissance et un petit poids de naissance et être associées à une prédisposition aux pathologies cardiovasculaires et métaboliques chez le jeune adulte. Dans tous 
Figure 11. Effets multigénérationnels - Effets transgénérationnels.

Les conséquences sur la descendance de l'exposition de rattes à la vinclozoline au cours de la gestation illustre bien cette notion. Pendant une fenêtre de temps assez courte (de 8 jours à 15 jours postconception), les rattes considérées comme F0, sont traitées à la vinclozoline par injections intraperitonéale. Le développement fœtal est perturbé. En postnatal, la descendance, considérée comme F1, présente différentes pathologies. Chez les femelles, on observe une altération des gestations et surtout une augmentation de l'apparition de tumeurs. Les mâles sont les plus atteints avec une spermatogénèse perturbée, une apoptose des spermatogonies plus importante, une mobilité et une concentration spermatique amoindrie. Le temps d'exposition à la vinclozoline au cours de la gestation correspondant justement à l'initiation de la différenciation gonadique, il est aisé d'y associer les altérations de la gamétogenèse. La descendance de ces individus, la F2 ainsi que la F3 et la F4 (deux générations n'ayant pas été en contact avec la vinclozoline) présente les mêmes symptomes, démontrant qu'un perturbateur endocrinien peut induire des modifications de phénotype non seulement de manière multigénérationnelle (de F0 à F2) mais aussi de manière transgénérationnelle (de F0 à F4).

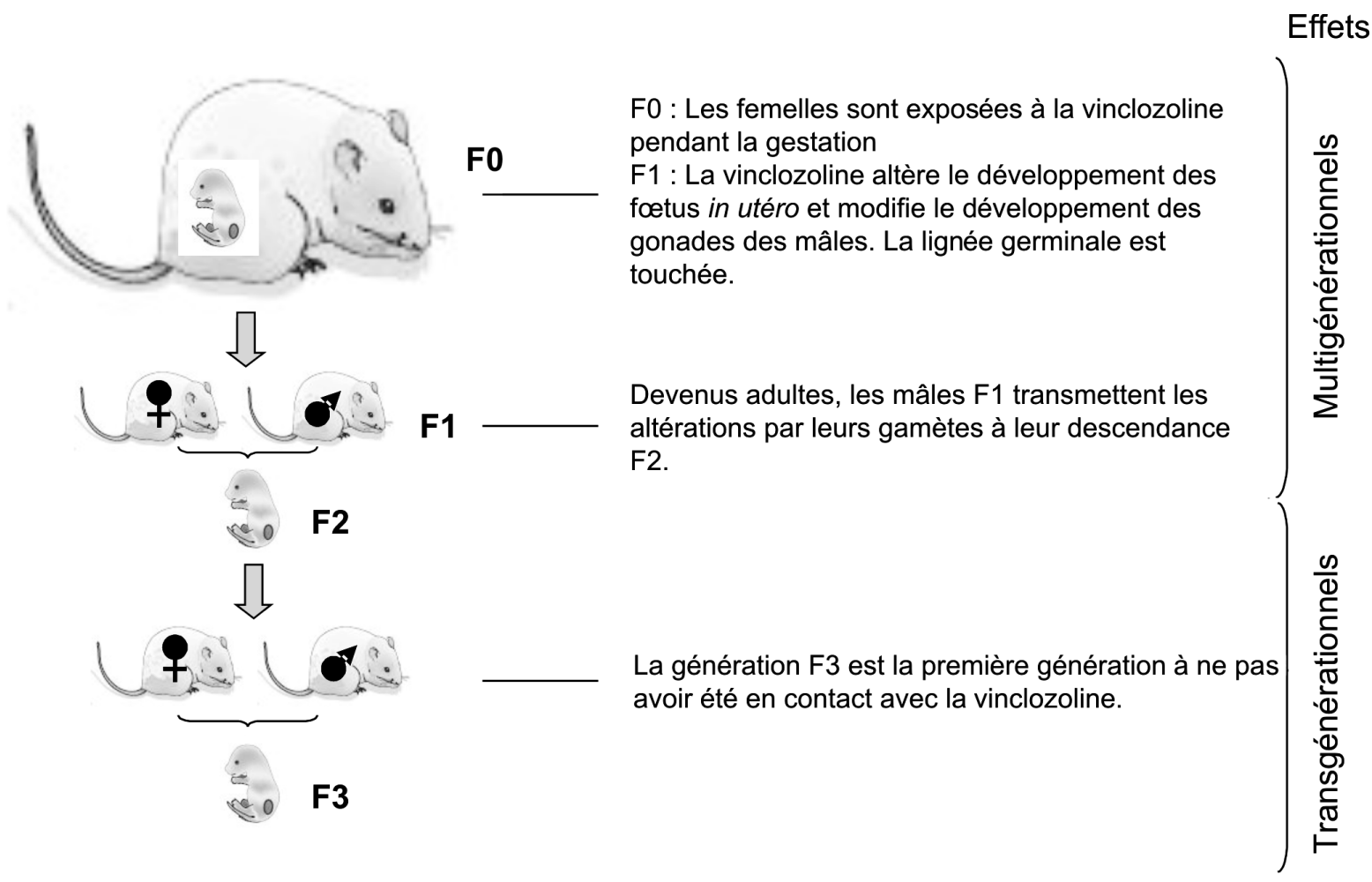

les cas, des altérations des marques épigénétiques apparaissent être au cœur de cette «mémoire» d'un stress nutritionnel (Rosenfeld 2010).

\section{4 / Perturbateurs endocriniens et effets transgénérationnels}

Les perturbateurs endocriniens sont des produits chimiques très variés présents dans l'environnement, qui affectent les fonctions endocriniennes en mimant les actions des hormones, en les bloquant, en altérant la signalisation intracellulaire ou en perturbant la synthèse hormonale (Skinner et al 2008). L'exposition à certains perturbateurs endocriniens, tels que le bisphenol-A (BPA), le dichlorodiphenyltrichloroéthane (insecticide mieux connu sous le nom de DDT), le diethylstilbestrol (DES) ou la vinclozoline, au cours de la vie embryonnaire, influencent plus particulièrement la reproduction et la fertilité de l'adulte. Dans le cas de la vinclozoline, ces effets se manifestent sur plusieurs générations. L'exposition de rattes femelles gravides (F0) à ce perturbateur endocrinien (entre 8 et $15 \mathrm{j}$ de gestation, une exposition plus tardive n'a pas d'effet), altère la fertilité et la fréquence d'apparition de pathologies chez les descendants. Chez les descendants femelles, la fertilité est peu affectée mais différents types de tumeurs apparaissent (Nilsson et al 2008). Chez les mâles, une baisse de la fertilité due à un défaut de spermatogénèse est transmissible aux générations suivantes, jusqu'en F4, ce qui peut être considéré comme une transmission transgénérationnelle (Anway et al 2006, figure 11). Les analyses d'expression des gènes testiculaires chez les fœtus (à $16 \mathrm{j}$ post-fécondation), démontrent au moins pour les deux premières générations, que les modifications de patrons d'expression des gènes induites par l'exposition à la vinclozoline sont les mêmes. Mais la majorité des gènes présentent une expression quasi normale chez les embryons de la troisième génération. De manière étonnante, les gènes les plus touchés sont ceux codant pour des enzymes impliqués dans les modifications épigénétiques (Anway et al 2008). Dans ce modèle expérimental, la relation directe entre les modifica- tions de la méthylation de l'ADN et celles de l'expression génique est encore controversée (Inawaka et al 2009, Stouder et al 2009). En revanche, dans le cas d'une exposition aux phytooestrogènes (Lyn-Cook et al 1995) ou au DES (Li et al 2003), des altérations de la méthylation de certains loci est bien démontrée.

Des données actuelles de la littérature il ressort : i) l'importance de la fenêtre d'exposition, en fonction du moment de 1'exposition aux perturbateurs endocriniens, les effets sur la descendance peuvent être tout à fait différents, ii) les différences de phénotype en fonction du sexe des descendants, les mâles présentant une plus grande sensibilité du moins pour l'aspect reproduction enfin iii) une transmission sur quelques générations mais qui s'estompe ensuite. Les cas rapportés à ce jour font état de trois ou quatre générations, ce qui peut être interprété différemment et analysé en terme respectivement de transmission multigénérationnelle ou de transmission transgénérationnelle (figure 11). 
Les données présentées ci-dessus montrent que des modifications d'activités géniques induites au niveau cellulaire par les marques épigénétiques contribuent aux variations phénotypiques. Ces marques sont impliquées dans l'élaboration de caractères phénotypiques complexes et peuvent exercer leurs effets sur quelques générations mais aussi être effacées.

\section{5 / Modèles d'études : des vrais jumeaux humains aux clones bovins}

La transmission «sur quelques générations» seulement distingue l'hérédité épigénétique de l'hérédité génique. Ecartant ici la question fondamentale du rôle évolutif de cette hérédité «molle» dont une meilleure connaissance des mécanismes moléculaires conduit à enrichir l'héritage de la pensée Darwinienne (Jablonska et Lamb 2002), intéressons-nous à une question plus finalisée : comment, à partir de l'analyse des phénotypes et dans une démarche de sélection, faire la part entre les variations inter-individuelles dues au polymorphisme des séquences d'ADN (polymorphisme allélique) et celles dues à des modifications épigénétiques?

Cette question reçoit un début de réponse chez Arabidopsis thaliana où des variants épialléliques identifiés par le niveau de méthylation variable de séquences d'ADN pourtant identiques apparaissent jouer un rôle important dans l'héritabilité de la période de floraison ou la hauteur de la plante (Johannes et al 2009). Mais cette même question est encore très peu documentée chez l'animal. Elle est pourtant d'importance pour une meilleure précision de la sélection génétique de caractères d'élevage : chez une espèce comme le bovin par exemple, où l'intervalle de génération est d'environ 4 à 5 ans, un effet épigénétique altérant un caractère d'intérêt comme la fertilité jusqu'à la quatrième génération (comme dans l'exemple présenté ci-dessus avec le rat) soit pendant quinze à vingt ans, pourrait être écarté dés la première génération.

Pour évaluer la prévalence des variations épigénétiques dans une population donnée et mesurer ensuite leurs effets sur des caractères complexes, les individus génétiquement identiques sont d'excellents modèles, toute différence constatée dans leur biologie, physiologie ou comportement pouvant être potentiellement une conséquence directe de l'intégration des informations environnementales. De telles études ont à ce jour été conduites essentiellement dans l'espèce humaine. La plupart des paires de jumeaux monozygotes manifestent des discordances phénotypiques (Cheung et al 2003, Sharma et al 2005). Récemment, il a été montré par l'étude de 160 couples de jumeaux monozygotes âgés de 3 à 74 ans, que les jumeaux, élevés séparément ou ayant eu des modes de vie très différents (habitudes nutritionnelles, activité physique, consommation de tabac, d'alcool et de médicaments), présentent des profils épigénétiques plus variables que ceux de jumeaux ayant vécu ensemble plus longtemps ou ayant partagé des environnements et des expériences similaires (Fraga et al 2005) suggérant qu'une part de l'influence du milieu pourrait être traduite en modifications épigénétiques.

Ces données confirment bien que les facteurs environnementaux peuvent affecter la lecture du patrimoine génétique d'un organisme et expliquer certaines des différences en matière de risque de maladies révélées entre jumeaux identiques. Des incidents épigénétiques mineurs apparus au cours des phases de différenciation cellulaire pourraient expliquer les différences phénotypiques qui permettent de distinguer les jeunes jumeaux. Par la suite, de nouveaux changements épigénétiques induits par des facteurs environnementaux, augmentent progressivement l'individualité de chacun d'eux. L'altération de la méthylation du gène H19 chez une jumelle monozygote souffrant du syndrome de Silver Russel alors que sa jumelle est parfaitement saine (Yamazawa et al 2008) en est une illustration convaincante.

Chez les mammifères d'élevage, les animaux issus de clonage pourraient devenir des modèles de recherche pertinents pour ces analyses, puisque ce n'est pas une paire d'individus mais plusieurs individus de même génotype nucléaire qui pourraient être utilisés dans les protocoles expérimentaux.

C'est le cas notamment avec les bovins où l'efficacité du clonage est sensiblement plus élevée que chez les autres mammifères d'élevage (environ $5 \%$ ). Chez cette espèce, il est possible d'obtenir régulièrement des lots de clones adultes à partir d'un génotype donneur d'intérêt, alors même que le taux de succès exprimé en nombre de veaux viables par rapport au nombre d'embryons transplantés, peut être très variable. La qualité des productions de ces animaux (lait, viande) n'est pas différente de celles d'animaux témoins issus de reproduction sexuée même si pour certains tissus de subtiles différences peuvent apparaître au cours du dévelop- pement fotal mais s'estomper au cours des premiers mois du développement postnatal (Heyman et al 2007, CassarMalek et al 2010).

Nous avons tiré bénéfice de cette situation pour comparer le taux de méthylation de l'ADN de bovins adultes clonés. Pour cela nous avons mesuré, à l'aide d'une technique très sensible d'électrophorèse capillaire, le taux de cytosines méthylées de l'ADN de leucocytes circulants de 38 femelles adultes issues par clonage de 9 donneuses différentes, (donc de 9 génotypes différents), réparties en autant de lots de 2 à 8 animaux génétiquement identiques, ou pour le moins très semblables puisque dérivés du même animal donneur (de Montera et al 2010). Les résultats montrent que les variations individuelles entre animaux clonés de même génotype sont plus importantes que les variations individuelles entre animaux clonés de génotypes différents. La variabilité du taux global de méthylation de l'ADN est aussi plus grande entre animaux clonés (issus du même génotype donneur) qu'entre jumelles (figure 12).

Il ressort de ces travaux que les copies génétiques obtenues en reprogrammant en plusieurs exemplaires un même génome, grâce au transfert de noyaux, sont épigénétiquement très différentes. L'utilisation des animaux issus du clonage permet une approche expérimentale rigoureuse pour évaluer, toutes conditions étant égales par ailleurs (génotype, conduite du troupeau...), la contribution de l'epigénome à la variabilité phénotypique individuelle.

Les variations épigénétiques mises en évidence entre organismes issus d'un même génome sont à considérer comme autant de signatures de leur adaptabilité aux contraintes environnementales majeures auxquelles est exposé ce génome dès le tout premier stade du développement. Les jumeaux mais surtout les clones animaux sont à considérer d'abord comme des modèles pour des recherches permettant de mesurer à partir de l'étude fine des caractères phénotypiques de chaque individu la contribution de l'épigénétique à la variation de ces caractères, ceci pour un génotype donné. La prise en compte de ces signatures valoriserait l'utilisation du génotype étudié. Sur un plan plus fondamental elle renseignerait la capacité d'un organisme à générer des variations phénotypiques héritables en réponse à des changements de son environnement (Kirschner et Gerhart 1998). L'épigénétique est bien un enjeu pour la sélection animale. 
Figure 12. Variabilité épigénétique des animaux issus du transfert nucléaire.

Une part importante de l'inefficacité du transfert nucléaire est due aux altérations épigénétiques subies par le noyau somatique au moment de sa reprogrammation en noyau zygotique. Puisque certains individus passent ce crible épigénétique, notre question était de savoir si ces animaux, de phénotype normal, avaient aussi une épigénome normal. Nous avons donc analysé le taux de méthylation globale de 38 femelles issues du clonage, représentatives de 5 génotypes différents pour la race Simmental et de 4 génotypes pour la race Holstein. Une série de 13 paires de jumelles (Simmental) a aussi été analysée.

A. Les individus d'un même génotype sont présentés en colonne. Le pourcentage de méthylation des cytosines a été déterminé par électrophorèse capillaire pour chaque individu (de 10 à 30 déterminations par échantillons ; les analyses statistiques révèlent une hyperméthylation des clones Simmental en comparaison avec les paires de jumelles Simmental $(6,5 \pm 0,01$ versus 5,38 $\pm 0,01$, test-t par paires $p<0,001)$ et en comparaison avec les clones Holstein $(6,5 \pm 0,01$ versus 5,09 $\pm 0,02$, test- $t$ par paires $p<0,001$ ).

B. Le plus intéressant est l'analyse de la variation de la méthylation globale pour l'ensemble des individus. Toutes les vaches issues du transfert nucléaire utilisant les mêmes cellules somatiques partagent le même patrimoine génétique nucléaire. En calculant la déviation individuelle par rapport à la moyenne de méthylation obtenue pour des individus d'un même génotype, il apparaît clairement que les clones Holstein ont un épigénome statistiquement plus variable que les clones Simmental et les paires de jumelles. Ces analyses révèlent une étonnante plasticité épigénétique chez des clones en bonne santé.

Cette étude a été menée en collaboration avec l'Université de Wuppertal, I'Institute of Molecular Animal Breeding and Biotechnology/LAFUGA de Munich et I'Institute of Animal Breeding and Genetics, de l'Université de Vienne (d'après de Montera et al 2010).

A

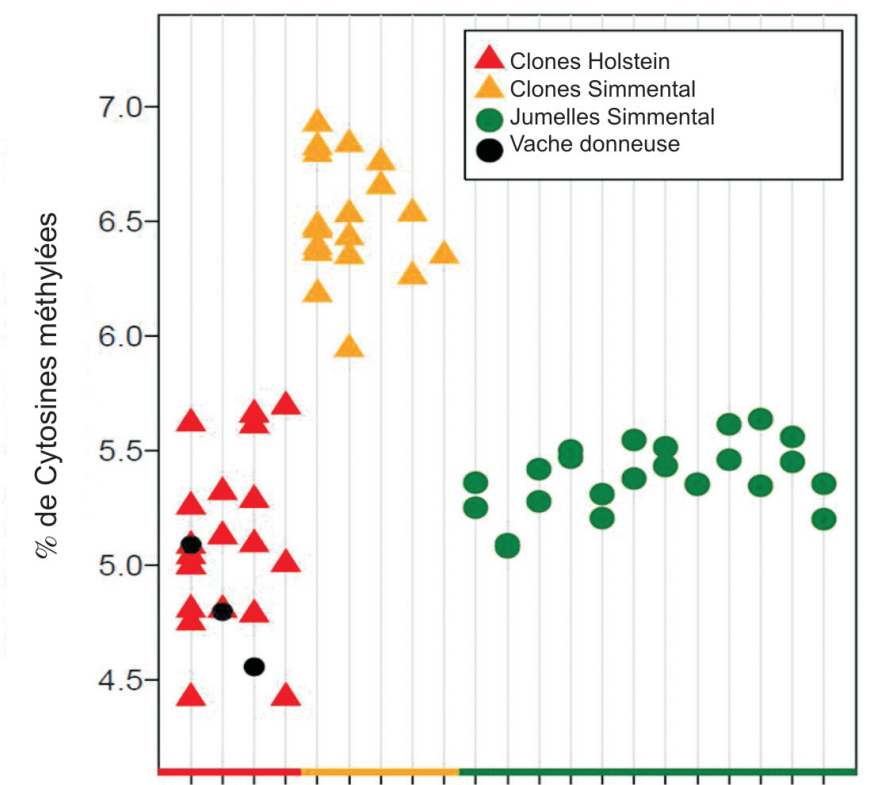

Génotypes Holstein, $(n=4)$

\section{Conclusion}

Les données présentées dans cet article révèlent l'importance des modifications épigénétiques dans l'expression des caractéristiques physiques d'un animal, c'est-à-dire dans la construction de son phénotype. Elles indiquent aussi que les variations de séquence d'ADN ne sont pas seules à l'origine de phénotypes héritables.

Des réseaux de laboratoires dédiés à l'étude des régulations épigénétiques chez l'Homme et chez la souris (www.epigenome-neo.net) permettent d'accéder à des données moléculaires essentielles pour comprendre comment s'élabore un phénotype et comment ce phénotype évolue en fonction de l'environnement et au cours du temps. Un projet similaire de

\section{B}

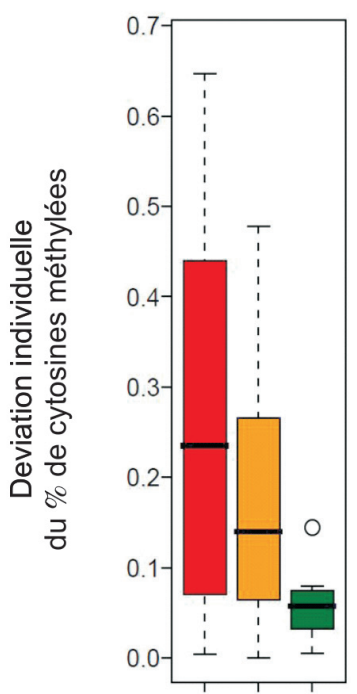

Paires de jumelles, $(n=13)$ réseau de laboratoires consacrés aux mammifères d'élevage est en cours de construction. Cette dynamique scientifique tire parti d'un développement très rapide des technologies mises au point pour caractériser chaque type de modifications épigénétiques pour l'ensemble du génome. C'est notamment le cas pour les séquences méthylées de l'ADN qui peuvent être caractérisées très précisément en associant à une immunoprécipitation de l'ADN méthylé (MeDIP), un séquençage à haut débit des fragments immunoprécipités (Tost 2008).

La création d'une première carte de l'épigénome bovin conduite en race Holstein fait l'objet d'un tout nouveau programme de recherche de l'INRA, soutenu par l'Agence Nationale de la Recherche et par les professionnels de l'Elevage, le programme EpigRAni.
Ce programme permettra de définir comment et jusqu'à quel point les données épigénétiques pourront être intégrées dans l'analyse génétique des populations bovines. Il s'appuiera sur l'étude de la cinétique d'acquisition des marques épigénétiques au cours du développement embryonnaire et fœtal et l'analyse de leurs modifications en fonction de l'état physiologique des animaux ou d'un tissu d'intérêt zootechnique, l'épithélium de la glande mammaire. Il intégrera évidemment les informations sur les séquences génomiques de chaque individu.

Avec le séquençage du génome bovin, une nouvelle transition s'ouvre en sélection animale puisqu'il sera possible de prédire le potentiel d'un reproducteur à partir de l'analyse de 
son génome, sans recours à son phénotype ou à celui de son descendant (Bidanel et al 2008). La prise en compte de mesures épigénétiques et de leurs variations (au cours de la vie de l'animal, entre tissus à l'origine des performances productives) pourra renforcer cette évolution de la sélection animale. Elle donne à l'analyse des phénotypes un rôle essentiel et rend urgent la standardisation des données tant zootechniques que physiologiques et moléculaires (et des procédures de leur recueil) qu'il est possible maintenant d'accumuler massivement sur chaque individu d'une population animale soumise à sélection (Hugues et al 2008).

L'épigénétique s'invite non seulement dans les questionnements fondamentaux pour expliquer les variations de caractères zootechniques qui ne peuvent être prises en compte par l'étude de l'effet additif des gènes mais aussi dans les stratégies qui devront être construites pour anticiper sur la nécessaire adaptation les animaux d'élevage aux modifications tant physiques (modifications du climat) qu'économique (évolution des structures et des modes de conduite d'élevage) de leur environnement. L'épigénétique a une dimension explicative des phénotypes, dont les modèles prédictifs de génétique quantitative utilisés à ce jour se dédouanent (Hill et al 2008). Cette dimension pourrait prendre toute sa mesure dans la perspective d'une orientation rapide des objectifs de la sélection animale face à des modifications importantes de l'environnement.

\section{Remerciements}

Les auteurs remercient leurs collègues de l'Unité de Biologie du
Développement et Reproduction pour leurs remarques et critiques constructives lors de la préparation du manuscrit et pour leurs discussions parfois animées autour de l'épigénétique et de la définition de son rôle en élevage. Ils sont reconnaissants à tous les membres de l'Atelier de production d'embryons de ruminants et de l'Unité Centrale d'Expérimentation Animale pour leur implication quotidienne dans la préparation et le suivi des animaux qui ont permis de produire les données expérimentales du laboratoire présentées dans cet article.

Les auteurs tiennent également à remercier la Commission EuropéenneDirection E03 - sécurité des systèmes alimentaires - pour le soutien financier apporté au laboratoire dans le cadre du programme européen SABRE (Cutting Edge genomics for Sustainable Animal Breeding ; contrat-CT-2006-01625).

\section{Références}

Adenot P.G., Szöllösi M.S., Geze M., Renard J.P., Debey P., 1991. Dynamics of paternal chromatin changes in live one-cell mouse embryo after natural fertilization. Mol. Reprod. Dev., 28, 23-34.

Amarger V., Nguyen M., Van Laere A.S., Braunschweig M., Nezer C., Georges M., Andersson L., 2002. Comparative sequence analysis of the INS-IGF2-H19 gene cluster in pigs. Mamm. Genome, 13, 388-398.

Anway M.D., Leathers C., Skinner M.K. 2006. Endocrine disruptor vinclozolin induced epigenetic transgenerational adult-onset disease. Endocrinology, 147, 5515-5523.

Anway M.D., Rekow S.S., Skinner M.K., 2008. Transgenerational epigenetic programming of the embryonic testis transcriptome. Genomics, 91, 30-40.

Aravin A.A., Bourc'his D., 2008. Small RNA guides for de novo DNA methylation in mammalian germ cells. Genes Dev., 22, 970975.

Barchuk A.R., Cristino A.S., Kucharski R., Costa L.F., Simões Z.L., Maleszka R., 2007. Molecular determinants of caste differentiation in the highly eusocial honeybee Apis mellifera. BMC Dev. Biol., 7, 70-79.

Barker D.J., 2007. The origins of the developmental origins theory. J Int. Med., 261, 412-417.

Barker D.J., Osmond C., Kajantie E., Eriksson J.G., 2009. Growth and chronic disease: findings in the Helsinki Birth Cohort. Ann. Hum. Biol., 36,445-458.

Barroso-del Jesus A., Lucena-Aguilar G., Menendez P., 2009. The miR-302-367 cluster as a potential stemness regulator in ESCs. Cell Cycle, 8, 394-398

Beaujean N., Martin C., Debey P., Renard J.P., 2005. Reprogramming and Epigenesis. Med. Sci., 21, 412-421.

Bidanel J.P, Boichard D., Chevalet C., 2008 De la génétique à la génomique. In : Numéro spécial Anniversaire, 20 ans de recherches en productions animales à l'INRA. B. Charley, P. Herpin, J.M. Perez (Eds). INRA Prod. Anim., $21,15-32$.

Braunschweig M.H., Van Laere A.S., Buys N., Andersson L., Andersson G., 2004. IGF2 antisense transcript expression in porcine postnatal muscle is affected by a quantitative trai nucleotide in intron 3. Genomics, 84, 10211029 .

Byrne K., Colgrave M.L., Vuocolo T., Pearson R., Bidwell C.A., Cockett N.E., Lynn D.J., Fleming-Waddell J.N., Tellam R.L., 2010 The imprinted retrotransposon-like gene PEG11 (RTL1) is expressed as a full-length protein in skeletal muscle from Callipyge sheep. PLoS One, 5(1):e8638.

Cameron N.M., Shahrokh D., Del Corpo A., Dhir S.K., Szyf M., Champagne F.A, Meaney M.J., 2008. Epigenetic programming of phenotypic variations in reproductive strategies in the rat through maternal care. Neuroendocrinol., 6, 795-801.

Cassar-Malek I., Picard B., Jurie C., Listrat A., Guillomot M., Chavatte-Palmer P., Heyman Y. 2010. Myogenesis Is Delayed in Bovine Fetal Clones. Cloning Stem Cells, sous presse.

Cattanach B.M., Beechey C.V., Peters J., 2004. Interactions between imprinting effects in the mouse. Genetics, 168, 397-413.

Charlier C., Segers K., Wagenaar D., Karim L., Berghmans S., Jaillon O., Shay T. Weissenbach J., Cockett N., Gyapay G, Georges M., 2001a. Human-ovine comparative sequencing of a $250-\mathrm{kb}$ imprinted domain encompassing the callipyge (clpg) locus and identification of six imprinted transcripts: DLK1, DAT, GTL2, PEG11, antiPEG11, and MEG8. Genome Res., 11, 850-862.

Charlier C., Segers K., Karim L., Shay T., Gyapay G., Cockett N., Georges M., 2001b. The callipyge mutation enhances the expression of coregulated imprinted genes in cis without affecting their imprinting status. Nat Genet., 27, 367-369.
Chen T., Li E., 2004 Structure and function of eukaryotic DNA methyltransferases Curr. Top. Dev. Biol., 60, 55-89.

Cheung V.G., Bruzel A., Burdick J.T., Morley M., Devlin J.L., Spielman R.S., 2008. Monozygotic twins reveal germline contribution to allelic expression differences. Am. J. Hum. Genet., 82, 1357-1360.

Cockett N.E., Jackson S.P., Shay T.L., Nielsen D., Moore S.S., Steele M.R., Barendse W., Green R.D., Georges M., 1994. Chromosomal localization of the callipyge gene in sheep (Ovis aries) using bovine DNA markers. Proc. Natl. Acad. Sci. USA., 91, 3019-3023

Cockett N.E., Jackson S.P., Shay T.L., Farnir F., Berghmans S., Snowder G.D., Nielsen D.M., Georges M., 1996. Polar overdominance at the ovine callipyge locus. Science, 273(5272), 236-238

Costa F.F., 2008. Non-coding RNAs, epigenetics and complexity. Gene, 410, 9-17.

de Koning D.J., Rattink A.P., Harlizius B., van Arendonk J.A., Brascamp E.W., Groenen M.A., 2000.Genome-wide scan for body composition in pigs reveals important role of imprinting.Proc. Natl. Acad. Sci. USA, 97, 7947-7950.

Eckhardt F., Lewin J., Cortese R., Rakyan V.K., Attwood J., Burger M., Burton J., Cox T.V., Davies R., Down T.A., Haefliger C., Horton R., Howe K., Jackson D.K., Kunde J., Koenig C., Liddle J., Niblett D., Otto T., Pettett R., Seemann S., Thompson C., West T., Rogers J., Olek A., Berlin K., Beck S., 2006 .DNA methylation profiling of human chromosomes 6, 20 and 22. Nat. Genet., 38, 1378-1385.

Foret S., Kucharski R., Pittelkow Y., Lockett G.A, Maleszka R., 2009. Epigenetic regulation of the honey bee transcriptome: unravelling the nature of methylated genes. BMC Genomics, $10,472-483$

Fraga M.F., Ballestar E., Paz M.F., Ropero S., Setien F., Ballestar M.L., Heine-Suñer D., 
Cigudosa J.C., Urioste M., Benitez J., BoixChornet M., Sanchez-Aguilera A., Ling C., Carlsson E., Poulsen P., Vaag A., Stephan, Z., Spector T.D, Wu Y.Z, Plass C., Esteller M., 2005. Epigenetic differences arise during the lifetime of monozygotic twins. Proc. Natl. Acad. Sci. USA, 102, 10604-10609.

Freking B.A., Murphy S.K., Wylie A.A., Rhodes S.J., Keele J.W., Leymaster K.A., Jirtle R.L., Smith T.P., 2002. Identification of the single base change causing the callipyge muscle hypertrophy phenotype, the only known example of polar overdominance in mammals. Genome Res., 12, 1496-1506.

Gabory A., 2008. Etude de la fonction de l'ARN non codant $H 19$ et de l'empreinte parentale au locus H19-IGF2 dans les modèles murins transgéniques. Thèse es Sciences, Ecole Doctorale Logique du vivant, Université Paris VII-Denis Diderot, Paris, France, 168p.

Gabory A., Dandolo L., 2005. Epigenetics and development: genomic imprinting. Med. Sci., 21, 390-395.

Gehring M., Henikoff S., 2007. DNA methylation dynamics in plant genomes. Biochim. Biophys. Acta, 1769, 276-286.

Gheorghe C.P., Goyal R., Mittal A., Longo L.D., 2010. Gene expression in the placenta: maternal stress and epigenetic responses. Int. J. Dev. Biol., 54, 507-523.

Gluckman P.D., Hanson M.A., Cooper C., Thornburg K.L., 2008. Effect of in utero and early-life conditions on adult health and disease. N. Engl. J. Med., 359, 61-73.

Goldberg A.D., Allis C.D., Bernstein E., 2007. Epigenetics: a landscape takes shape. Cell, 128, 635-638.

Hayashi K., Lopes S.M., Tang F., Surani M. A., 2008. Dynamic equilibrium and heterogeneity of mouse pluripotent stem cells with distinct functional and epigenetic states. Stem Cell., 3, 391-401.

Heyman Y., Chavatte-Palmer P., Berthelot V., Fromentin G., Hocquette J.F., Martignat L., Renard J.P., 2007. Assessing the quality of products from cloned cattle: an integrative approach. Theriogenology, 67, 134-141.

Hill W.G., Goddard M.E., Visscher P.M., 2008. Data and theory point to mainly additive genetic variance for complex traits. PLoS Genet., 4(2):e1000008.

Holliday R., Pugh J. E., 1975. DNA modification mechanisms and gene activity during development. Science, 187, 226-232.

Hughes L.M., Bao J., Hu Z.L., Honavar V., Reecy J.M., 2008. Animal trait ontology: The importance and usefulness of a unified trait vocabulary for animal species. J. Anim. Sci., 86, 1485-1491.

Inawaka K., Kawabe M., Takahashi S., Doi Y., Tomigahara Y., Tarui H., Abe J., Kawamura S., Shirai T., 2009. Maternal exposure to antiandrogenic compounds, vinclozolin, flutamide and procymidone, has no effects on spermatogenesis and DNA methylation in male rats of subsequent generations. Toxicol. Appl. Pharmacol., 237,178-187.

Jablonka E., Lamb M.J., 2002. The changing concept of epigenetics. Ann. N.Y. Acad. Sci., 981, 82-96.

Jacob F., Monod M., 1961. Genetic regulatory mechanisms in the synthesis of proteins. J. Mol. Biol., 3, 318-356.
Jansson T., Powell T.L., 2007. Role of the placenta in fetal programming: underlying mechanisms and potential interventional approaches. Clin. Sci., 113, 1-13.

Jeon J.T., Carlborg O., Törnsten A., Giuffra E., Amarger V., Chardon P., Andersson-Eklund L., Andersson K., Hansson I., Lundström K., Andersson L., 1999. A paternally expressed QTL affecting skeletal and cardiac muscle mass in pigs maps to the IGF2 locus. Nat. Genet., 21, 157-158.

Johannes F., Colot V., Jansen R.C., 2009. Epigenome dynamics: a quantitative genetics perspective. Nat. Rev. Genet., 9, 883-890.

Kirschner M., Gerhart J., 1998. Evolvability. Proc. Natl. Acad. Sci. USA, 95, 8420-8427.

Kitano H., 2004. Biological robustness Nat. Rev. Genet., 11, 826-837.

Kouzarides T., 2007. Chromatin modifications and their function. Cell, 128, 693-705.

Kucharski R., Maleszka J., Foret S., Maleszka R., 2008. Nutritional control of reproductive status in honey bees via DNA methylation. Science, 319, 1827-1830.

Li S., Hursting S.D., Davis B.J., McLachlan J.A., Barrett J.C., 2003. Environmental exposure, DNA methylation, and gene regulation: lessons from diethylstilbesterol-induced cancers. Ann. N. Y. Acad. Sci. USA, 983, 161-169.

Lopes S., Lewis A., Hajkova P., Dean W., Oswald J., Forné T., Murrell A., Constância M., Bartolomei M., Walter J., Reik W., 2003. Epigenetic modifications in an imprinting cluster are controlled by a hierarchy of DMRs suggesting long-range chromatin interactions. Hum. Mol. Genet., 12, 295-305.

Luedi P.P., Dietrich F.S., Weidman J.R., Bosko J.M., Jirtle R.L., Hartemink A.J., 2007. Computational and experimental identification of novel human imprinted genes. Genome Res., 17, 1723-1730.

Luger K., Richmond T.J., 1998. The histone tails of the nucleosome. Curr. Opin. Genet. Dev., 8, 140-146.

Lyn-Cook B.D., Blann E., Payne P.W., Bo J., Sheehan D., Medlock K., 1995. Methylation profile and amplification of proto-oncogenes in rat pancreas induced with phytoestrogens. Proc. Soc. Exp. Biol. Med., 208,116-119.

Mallory A.C., Vaucheret H., 2006. Functions of microRNAs and related small RNAs in plants. Nat. Genet., 38, Suppl, S31-S36.

Martinez A.M., Cavalli G., 2006. The role of polycomb group proteins in cell cycle regulation during development. Cell Cycle, 5, 11891197.

Mattick J.S., 2009. The genetic signatures of noncoding RNAs. PLoS Genet., 5(4): 1000459

McGowan P.O., Meaney M.J., Szyf M., 2008. Diet and the epigenetic (re)programming of phenotypic differences in behavior. Brain Res., 1237, 12-24.

McGrath J., Solter D., 1984. Completion of mouse embryogenesis requires both the maternal and paternal genomes. Cell, 37, 179-183.

Molinier J., Ries G., Zipfel C., Hohn B., 2006. Transgeneration memory of stress in plants. Nature, 442, 1046-1049.

Montera B., El Zeihery D., Müller S., Jammes H., Brem G., Reichenbach H.D,
Scheip F., Chavatte-Palmer P., Zakhartchenko V., Schmitz O.J., Wolf E., Renard J.P, Hiendleder S., 2010. Quantification of leukocyte genomic 5-methylcytosine levels reveals epigenetic plasticity in healthy adult cloned cattle. Cloning Stem Cells, sous presse.

Morange M., 2009. What history tells us XVII. Conrad Waddington and the nature of life.J. Biosci., 2, 195-198.

Murphy S.K., Nolan C.M., Huang Z., Kucera K.S., Freking B.A., Smith T.P., Leymaster K.A., Weidman J.R., Jirtle R.L., 2006. Callipyge mutation affects gene expression in cis: a potential role for chromatin structure. Genome Res., 16, 340-346.

Murrell A., Heeson S., Reik W., 2004. Interaction between differentially methylated regions partitions the imprinted genes Igf2 and H19 into parent-specific chromatin loops. Nat. Genet., 36, 889-893.

Nezer C., Moreau L., Brouwers B., Coppieters W., Detilleux J., Hanset R., Karim L., Kvasz A., Leroy P., Georges M., 1999. An imprinted QTL with major effect on muscle mass and fat deposition maps to the IGF2 locus in pigs. Nat. Genet., 21, 155-156.

Nezer C., Collette C., Moreau L., Brouwers B., Kim J.J., Giuffra E., Buys N., Andersson L., Georges M., 2003. Haplotype sharing refines the location of an imprinted quantitative trait locus with major effect on muscle mass to a $250-\mathrm{kb}$ chromosome segment containing the porcine IGF2 gene. Genetics, 165 , 277-285.

Nilsson E.E, Anway M.D, Stanfield J., Skinner M.K., 2008.Transgenerational epigenetic effects of the endocrine disruptor vinclozolin on pregnancies and female adult onset disease. Reproduction, 135, 713-721.

Qiu X., Vu T.H., Lu Q., Ling J.Q., Li T., Hou A., Wang S.K., Chen H.L., Hu J.F., Hoffman A.R., 2008. A complex deoxyribonucleic acid looping configuration associated with the silencing of the maternal Igf2 allele. Mol. Endocrinol., 22, 1476-1488.

Reik W., 2007. Stability and flexibility of epigenetic gene regulation in mammalian development. Nature, 447, 425-432.

Riggs A.D., 1975. X inactivation, differentiation, and DNA methylation. Cytogenet. Cell Genet., 14, 9-25.

Robertson K.D., 2005. DNA methylation and human disease. Nat. Rev. Genet., 6, 597610.

Rosenfeld C.S., 2010. Animal models to study environmental epigenetics. Biol. Reprod., 82, 473-488.

Santillán M., Mackey M.C., 2008 Quantitative approaches to the study of bistability in the lac operon of Escherichia coli. J. R. Soc. Interface, 5, Suppl 1, S29-S39.

Schaefer C.B., Ooi S.K., Bestor T.H., Bourc'his D., 2007. Epigenetic decisions in mammalian germ cells. Science, 316, 398-399.

Schwartz Y.B., Pirrotta V., 2007. Polycomb silencing mechanisms and the management of genomic programmes. Nat. Rev. Genet., 8, 9-22.

Sharma A., Sharma V.K., Horn-Saban S., Lancet D., Ramachandran S., Brahmachari S.K., 2005. Assessing natural variations in gene expression in humans by comparing with monozygotic twins using microarrays. Physiol. Genomics, 21, 117-123. 
Skinner M.K., 2008. What is an epigenetic transgenerational phenotype? F3 or F2. Reprod. Toxicol., 25, 2-6.

Slack J.M., 2002. Conrad Hal Waddington: the last Renaissance biologist? Nat. Rev. Genet., 3, 889-895.

Song F., Mahmood S., Ghosh S., Liang P., Smiraglia D.J., Nagase H., Held W.A., 2009. Tissue specific differentially methylated regions (TDMR): Changes in DNA methylation during development. Genomics, 3, 130-139.

Sparmann A., Van Lohuizen, M., 2006 Polycomb silencers control cell fate, development and cancer. Nat. Rev. Cancer, 6, 846-856.

Stouder C., Paoloni-Giacobino A., 2010. Transgenerational effects of the endocrine disruptor vinclozolin on the methylation pattern of imprinted genes in the mouse sperm. Reproduction, 139, 373-379.

Strahl B.D., Allis C.D., 2000. The language of covalent histone modifications. Nature, 403, 41-45.

Surani M.A., Barton S.C., Norris M.L. 1984. Development of reconstituted mouse eggs suggests imprinting of the genome during gametogenesis. Nature, 308, 548-550.

Suter C.M., Martin D.I., 2010 Paramutation: the tip of an epigenetic iceberg? Trends Genet., 26, 9-14.
Suzuki M.M., Bird A., 2008. DNA methylation landscapes: provocative insights from epigenomics. Nat. Rev. Genet., 9, 465-476. Review.

Takahashi K.,Yamanaka, S., 2006 Induction of pluripotent stem cells from mouse embryonic and adult fibroblast cultures by defined factors. Cell, 126, 663-676.

Torres-Padilla M.E., 2008. Cell identity in the preimplantation mammalian embryo: an epigenetic perspective from the mouse. Hum. Reprod., 23, 1246-1252.

Tost J., 2008. DNA methylation and the mammalian genome. In: Epigenetics. J. Tost (Ed). Caister Academic Press, 63-103.

Ueda H.R., Hayashi S., Matsuyama S., Yomo T., Hashimoto S., Kay S.A., Hogenesch J.B., Iino M., 2004. Universality and flexibility in gene expression from bacteria to human. Proc. Natl. Acad. Sci. USA, 101, 3765-3769.

Van Laere A.S., Nguyen M., Braunschweig M., Nezer C., Collette C., Moreau L., Archibald A.L., Haley C.S., Buys N., Tally M., Andersson G., Georges M., Andersson L., 2003. A regulatory mutation in IGF2 causes a major QTL effect on muscle growth in the pig. Nature, 425, 832-836.

Vignon X., Heyman Y., Chavatte-Palmer P., Renard, J.P., 2008. Biotechnologies de la reproduction : le clonage des animaux d'élevage. In : Numéro spécial Anniversaire, 20 ans de recherches en productions animales à l'INRA. B. Charley, P. Herpin, J.M. Perez (Eds). INRA Prod. Anim., 21, 33-44.

Vuocolo T., Byrne K., White J., McWilliam S., Reverter A., Cockett N.E., Tellam R.L., 2007 Identification of a gene network contributing to hypertrophy in callipyge skeletal muscle. Physiol. Genomics, 28, 253-272

Weaver I.C., Cervoni N., Champagne F.A., D'Alessio A.C., Sharma S., Seckl J.R., Dymov S., Szyf M., Meaney M.J., 2004. Epigenetic programming by maternal behavior. Nat. Neurosci., 7, 847-854.

Weber M., Schübeler D., 2007. Genomic patterns of DNA methylation: targets and function of an epigenetic mark. Curr. Opin. Cell Biol., 19, 273-280.

West-Eberhard M.J., 2005. Phenotypic accommodation: adaptive innovation due to developmental plasticity. J. Exp. Zool. B. Mol. Dev. Evol., 304, 610-618.

Yamazawa K., Kagami M., Fukami M. Matsubara K., Ogata T., 2008. Monozygotic female twins discordant for Silver-Russell syndrome and hypomethylation of the H19-DMR J. Hum. Genet., 53, 950-955.

\section{Résumé}

L'épigénétique analyse les changements héritables de l'activité génique sans modification du patrimoine génétique nucléaire. Elle s'intéresse aux processus moléculaires qui modifient l'architecture de la chromatine, sélectionnant l'information génétique et contribuant à l'établissement des patrons d'expressions génique. Nous montrons à l'appui de données publiées que l'apposition des marques épigénétiques est séquentielle, réversible et/ou héritable. Ces marques peuvent être analysées et quantifiées finement à haut débit pour caractériser «l'épigénome». L'analyse fonctionnelle des régulations épigénétiques conduit à mettre en avant les notions de flexibilité et de robustesse. La flexibilité est patente lors de l'établissement d'une identité cellulaire («pourquoi toutes les cellules d'un même individu ne traitent elles pas l'information génétique de la même manière ?») et pour l'adaptation de l'individu à son environnement, le destin des abeilles devenant reines ou ouvrières en est un bon exemple. Mais le maintien de l'épigénome en l'état est tout aussi essentiel au bon développement des organismes impliquant a contrario, une robustesse des marques épigénétiques, cas des gènes soumis à empreinte parentale. La flexibilité des marques épigénétiques permet une adaptation transitoire à des modifications environnementales ; la robustesse révèle des possibilités d'adaptation à plus long terme, synonymes de stabilité des marques, dans certaines situations sur plusieurs générations. Cet article vise ainsi à montrer l'importance des processus épigénétiques dans le fonctionnement des génomes et avance l'idée qu'il serait judicieux d'intégrer les données moléculaires sur les états de l'épigénome dans les schémas de sélection dans une optique de maintien d'un développement durable de l'élevage.

\section{Abstract}

\section{Epigenetics and phenotype construction, a challenge for livestock production?}

Epigenetics refers to the inheritable changes of genomic activities that do not alter DNA sequences. It deals with the molecular mechanisms orchestrating chromatin remodelling, which leads to gene transcription or silencing. Here, we provide evidence from the published scientific literature that the epigenetic marks are apposed onto the genome in a sequential, reversible and/or inheritable manner. These marks can be finely measured to characterise the epigenome. The functional analysis of the epigenetic processes provides support to the two associated concepts of genome flexibility and robustness. Genome flexibility is involved in the acquisition of cell identity during differentiation (Why do not the various cellular types of an organism use the same genetic information in a similar manner?), and in the adaptation to environmental cues as illustrated by the mechanism underlying the fate of honeybees that become fertile queens or sterile workers. But the epigenome is also crucial for the development of individuals that requires the robustness of epigenetic marks as exemplified from parental imprinting studies. The flexibility of epigenetic marks is associated with transitory adaptation to environmental changes while robustness reveals long term processes associated with more stable marks that in some instances can pass over several generations. This review points to the importance of epigenetic processes for genome functions and proposes that the integration of the molecular data describing the epigenomic states could be considered as new variables in selection to preserve the sustainability of animal breeding.

H. JAMMES H., RENARD J.- P., 2010. Epigénétique et construction du phénotype, un enjeu pour les productions animales ? In : Robustesse, rusticité, flexibilité, plasticité, résilience... les nouveaux critères de qualité des animaux et des systèmes d'élevage. Sauvant D., Perez J.M. (Eds). Dossier Inra Prod. Anim., 23, 23-42. 